\title{
Development of a Catalyzed Diesel Particulate Filter Multi-zone Model for Simulation of Axial and Radial Substrate Temperature and Particulate Matter Distribution
}

\author{
Boopathi S. Mahadevan ${ }^{1}$ • John H. Johnson ${ }^{1} \cdot$ Mahdi Shahbakhti $^{1}$
}

Received: 2 January 2015 /Revised: 9 April 2015 / Accepted: 14 April 2015 / Published online: 16 May 2015

(C) Springer SIP, AG 2015

\begin{abstract}
The catalyzed particulate filter (CPF) is an important exhaust aftertreatment subsystem that is managed by the electronic control unit (ECU) of an engine. CPFs need periodic regeneration to avoid temperature exotherms and excess engine back pressure. To this end, a multi-zone particulate filter (MPF) model was developed in this research to serve as a simulation tool to provide on-board diagnostics (OBD) data for managing CPF active regeneration (AR). The MPF model runs in real time within the ECU to provide feedback on temperature and particulate matter (PM) loading distribution within each axial and radial zone of the filter substrate. The MPF model accounts for the internal and external heat transfer mechanisms, inlet temperature distribution using the fully developed boundary layer concept, and PM oxidation by thermal $\left(\mathrm{O}_{2}\right)$ - and $\mathrm{NO}_{2}$-assisted oxidation mechanisms. A calibration procedure was developed to calibrate the PM kinetics and heat transfer coefficients of the MPF model. The model shows the good capability to predict temperature and PM loading distribution within the filter.
\end{abstract}

Keywords Diesel particulate filter model $\cdot$ ECU based particulate filter model - Temperature distribution · Particulate loading distribution $\cdot$ Diesel exhaust emission control

Abbreviations
AR $\quad$ Active regeneration
B10 $\quad$ Diesel blend (ULSD) with 10\% Biodiesel

Boopathi S. Mahadevan bsingala@mtu.edu

Michigan Technological University, 815 RL Smith Building, 1400 Townsend Drive, Houghton, MI 49931, USA
B20 Diesel blend (ULSD) with 20\% Biodiesel

CFD Computational fluid dynamics

CPF Catalyzed particulate filter

$\mathrm{CO}_{2} \quad$ Carbon dioxide

DOC Diesel oxidation catalyst

DPF Diesel particulate filter

ECU Electronic control unit

MPF Multi-zone particulate filter

MTU Michigan Technological University

$\mathrm{NO}_{2} \quad$ Nitrogen dioxide

NO Nitrogen monoxide

OBD On-board diagnostics

$\mathrm{O}_{2} \quad$ Oxygen

PO Passive oxidation

PM Particulate matter

SCR Selective catalytic reduction

ULSD Ultra-low-sulfur diesel

1-D One dimensional

2-D Two dimensional

3-D Three dimensional

\section{Nomenclature}

$A_{\mathrm{amb}} \quad$ Surface area of outer surface $\left[\mathrm{m}^{2}\right]$

$\bar{A} \quad$ Average cross-sectional area $\left[\mathrm{m}^{2}\right]$

$A_{02} \quad$ Pre-exponential for thermal $\left(\mathrm{O}_{2}\right)$ PM oxidation $\left[\mathrm{m} \mathrm{K}^{-1} \mathrm{~s}^{-1}\right.$ ]

$A_{\mathrm{N} 02} \quad$ Pre-exponential for $\mathrm{NO}_{2}$-assisted PM oxidation $\left[\mathrm{m} \mathrm{K}^{-1} \mathrm{~s}^{-1}\right.$ ]

$A f_{\mathrm{i}, \mathrm{j}} \quad$ Cross-sectional area perpendicular to direction of heat transfer $\left[\mathrm{m}^{2}\right]$

$A r_{\mathrm{i}, \mathrm{j}} \quad$ Area normal to direction of heat transfer in the radial direction $\left[\mathrm{m}^{2}\right]$

$A s_{\mathrm{i}, \mathrm{j}} \quad$ Combined surface area of both inlet and outlet channels $\left[\mathrm{m}^{2}\right]$

C Constant $[-]$ 


\begin{tabular}{|c|c|c|c|}
\hline$c_{f}$ & $\begin{array}{l}\text { Specific heat of filter material }\left[\mathrm{J} \mathrm{kg}^{-1} \mathrm{~K}^{-1}\right] \\
\text { CPF inlet } \mathrm{NO}_{2} \text { concentration }[\mathrm{ppm}]\end{array}$ & $\dot{Q}_{\text {conv }}$ & $\begin{array}{l}\text { Convection between channel gases and filter wall } \\
\text { [W] }\end{array}$ \\
\hline $\mathrm{C}_{\mathrm{O} 2}$ & $\mathrm{CPF}$ inlet $\mathrm{O}_{2}$ concentration $[\mathrm{ppm}]$ & $\dot{Q}_{\mathrm{rad}}$ & Radiation between channel surfaces [W] \\
\hline $\begin{array}{l}c_{p} \\
\mathrm{C}_{\mathrm{PM}}\end{array}$ & $\begin{array}{l}\text { Constant pressure specific heat }\left[\mathrm{J} \mathrm{kg}^{-1} \mathrm{~K}^{-1}\right] \\
\text { CPF Inlet PM concentration }\left[\mathrm{mg} \mathrm{m}^{-3}\right]\end{array}$ & $\dot{Q}_{\text {reac }}$ & $\begin{array}{l}\text { Total energy released during PM cake exothermic } \\
\text { reactions [W] }\end{array}$ \\
\hline$c_{s}$ & Specific heat of PM cake $\left[\mathrm{J} \mathrm{kg}^{-1} \mathrm{~K}^{-1}\right]$ & $\dot{Q}_{\text {reac }, \mathrm{NO}_{2}}$ & Energy released during $\mathrm{NO}_{2}$-assisted $\mathrm{PM}$ cake \\
\hline$d$ & Side length of square channels [m] & & \\
\hline $\begin{array}{l}D \\
E_{O}\end{array}$ & Overall diameter of the CPF $[\mathrm{m}]$ & $\dot{Q}_{\text {reac }, \mathrm{O}_{2}}$ & $\begin{array}{l}\text { Energy released during thermal }\left(\mathrm{O}_{2}\right) \text { PM cake } \\
\text { exothermic reactions [W] }\end{array}$ \\
\hline$E_{\mathrm{O}_{2}}$ & $\begin{array}{l}\text { Activation energy for thermal }\left(\mathrm{O}_{2}\right) \text { PM oxidation } \\
{\left[\mathrm{J} \mathrm{gmol}^{-1}\right]}\end{array}$ & $r c_{i}$ & Radial distance of a zone from centerline [m] \\
\hline$E_{\mathrm{NO}_{2}}$ & $\begin{array}{l}\text { Activation energy for } \mathrm{NO}_{2} \text {-assisted } \mathrm{PM} \text { oxidation } \\
{\left[\mathrm{J} \mathrm{gmol}^{-1}\right]}\end{array}$ & $\begin{array}{l}\Delta r \\
R_{u}\end{array}$ & $\begin{array}{l}\text { Effective zone radius }[\mathrm{m}] \\
\text { Universal gas constant }\left[\mathrm{J} \mathrm{gmol}^{-1} \mathrm{~K}^{-1}\right]\end{array}$ \\
\hline $\begin{array}{l}F 1 \\
F 2\end{array}$ & Temperature factor $[-]$ & $\dot{S}_{c_{(t h)}}$ & Thermal $\left(\mathrm{O}_{2}\right)$-assisted PM cake oxidation rate \\
\hline $\begin{array}{l}F 2 \\
F_{3-1}\end{array}$ & $\begin{array}{l}\text { Mean to surface temperature ratio }[-] \\
\text { Radiation view factor between inlet of the chan- } \\
\text { nel to filter wall }[-]\end{array}$ & $\dot{S}_{c_{(N O 2)}}$ & $\begin{array}{l}\mathrm{NO}_{2} \text {-assisted PM cake oxidation rate }\left[\mathrm{kg} \mathrm{C}_{(\mathrm{s})}\right. \\
\left.\mathrm{m}^{-3} \mathrm{~s}^{-1}\right]\end{array}$ \\
\hline$F_{3-2}$ & $\begin{array}{l}\text { Radiation view factor between outlet of the } \\
\text { channel to filter wall }[-]\end{array}$ & $\begin{array}{l}S_{p} \\
t\end{array}$ & $\begin{array}{l}\text { Specific surface area of PM }\left[\mathrm{m}^{-1}\right] \\
\text { Time }[\mathrm{s}]\end{array}$ \\
\hline$h_{\mathrm{amb}}$ & $\begin{array}{l}\text { Ambient convective heat transfer coefficient } \\
{\left[\mathrm{W} \mathrm{m} \mathrm{m}^{-2} \mathrm{~K}^{-1}\right]}\end{array}$ & $\begin{array}{l}T \\
T_{\mathrm{amb}}\end{array}$ & $\begin{array}{l}\text { Average gas temperature of channels }[\mathrm{K}] \\
\text { Ambient temperature }[\mathrm{K}]\end{array}$ \\
\hline$h_{g}$ & Convective heat transfer coefficient $\left[\mathrm{W} \mathrm{m}^{-2} \mathrm{~K}^{-1}\right]$ & $T_{\text {exit }}$ & Filter exit gas temperature $[\mathrm{K}]$ \\
\hline$\Delta H_{\text {reac }}$ & $\begin{array}{l}\text { Heat of reaction for carbon oxidation via } \mathrm{O}_{2} \\
{\left[\mathrm{~J} \mathrm{~kg}^{-1}\right]}\end{array}$ & $\begin{array}{l}T f \\
T_{\text {in }}\end{array}$ & $\begin{array}{l}\text { Temperature of combined filter and PM cake }[\mathrm{K}] \\
\mathrm{CPF} \text { inlet temperature }\left[{ }^{\circ} \mathrm{C}\right]\end{array}$ \\
\hline $\mathrm{J} 1$ & Radiosity of channel inlet surface $\left[\mathrm{W} \mathrm{m}^{-2}\right]$ & $T_{m}$ & Mean exhaust gas temperature $[\mathrm{K}]$ \\
\hline $\mathrm{J} 2$ & Radiosity of filter wall surface $\left[\mathrm{W} \mathrm{m}^{-2}\right]$ & $T_{s}$ & Wall inner surface temperature $[\mathrm{K}]$ \\
\hline $\mathrm{J} 3$ & Radiosity of channel outlet surface [ $\left.\mathrm{W} \mathrm{m}^{-2}\right]$ & $T_{r}$ & Temperature at a given radial location $[\mathrm{K}]$ \\
\hline$k_{\mathrm{O}_{2}}$ & $\begin{array}{l}\text { Rate constant for thermal }\left(\mathrm{O}_{2}\right) \mathrm{PM} \text { oxidation } \\
{\left[\mathrm{m} \mathrm{s}^{-1}\right]}\end{array}$ & $\frac{t s_{\mathrm{i}, \mathrm{j}}}{t s}$ & $\begin{array}{l}\text { Average PM cake thickness in each zone }[\mathrm{m}] \\
\text { Average PM cake thickness across entire CPF }[\mathrm{m}]\end{array}$ \\
\hline $\begin{array}{l}k_{\mathrm{NO}_{2}} \\
k_{g}\end{array}$ & $\begin{array}{l}\text { Rate constant for } \mathrm{NO}_{2} \text { assisted } \\
\text { Thermal conductivity of channel gas }\end{array}$ & $\overline{t s_{i}}$ & $\begin{array}{l}\text { Average PM cake thickness in each radial zone } \\
{[\mathrm{m}]}\end{array}$ \\
\hline & {$\left[\mathrm{W} \mathrm{m}{ }^{-1} \mathrm{~K}^{-1}\right]$} & $u$ & Representative velocity in each zone $\left[\mathrm{m} \mathrm{s}^{-1}\right]$ \\
\hline$L$ & Axial length $[\mathrm{m}]$ & $u_{\mathrm{I}}$ & Average inlet channel velocity $\left[\mathrm{m} \mathrm{s}^{-1}\right]$ \\
\hline$L_{t}$ & Total length of CPF [m] & $u_{\mathrm{II}}$ & Average outlet channel velocity $\left[\mathrm{m} \mathrm{s}^{-1}\right]$ \\
\hline$\Delta L$ & Effective zone length [m] & $u_{s}$ & Average velocity through PM layer $\left[\mathrm{m} \mathrm{s}^{-1}\right]$ \\
\hline $\begin{array}{l}\Delta t \\
\dot{m}\end{array}$ & $\begin{array}{l}\text { Solver Time step [s] } \\
\text { Instantaneuos exhaust mass flow rate }\left[\mathrm{kg} \mathrm{s}^{-1}\right]\end{array}$ & $u_{s i}$ & $\begin{array}{l}\text { Average velocity through PM layer in each radial } \\
\text { zone }\left[\mathrm{m} \mathrm{s}^{-1}\right]\end{array}$ \\
\hline$\dot{m}_{i},_{j}$ & Mass flow rate entering each zone $\left[\mathrm{kg} \mathrm{s}^{-1}\right]$ & $u_{w}$ & Average velocity through wall layer $\left[\mathrm{m} \mathrm{s}^{-1}\right]$ \\
\hline $\begin{array}{l}m s_{i, j} \\
m s_{t}\end{array}$ & $\begin{array}{l}\text { Mass of PM in each zone }[\mathrm{kg}] \\
\text { Total mass of PM retained }[\mathrm{kg}]\end{array}$ & $u_{w i}$ & $\begin{array}{l}\text { Average velocity through wall layer in each radial } \\
\text { zone }\left[\mathrm{m} \mathrm{s}^{-1}\right]\end{array}$ \\
\hline$\dot{m}_{\text {total }}$ & Total mass flow rate into $\mathrm{CPF}\left[\mathrm{kg} \mathrm{s}^{-1}\right]$ & $V$ & Total volume of a zone $\left[\mathrm{m}^{3}\right]$ \\
\hline$N c_{i}$ & Number of cells in each radial zone $[-]$ & $V_{e}$ & Empty volume in each zone $\left[\mathrm{m}^{3}\right]$ \\
\hline$N c_{t}$ & Total number of cells $[-]$ & $V_{e s}$ & Empty volume accounting for PM cake $\left[\mathrm{m}^{3}\right]$ \\
\hline$N u_{\text {avg }}$ & $\begin{array}{l}\text { Average Nusselt number of the inlet and outlet } \\
\text { channel }\end{array}$ & $\begin{array}{l}V_{f} \\
V_{s}\end{array}$ & $\begin{array}{l}\text { Volume of filter in each zone }\left[\mathrm{m}^{3}\right] \\
\text { PM cake volume in each zone }\left[\mathrm{m}^{3}\right]\end{array}$ \\
\hline$N u_{\text {inlet }}$ & Nusselt number of the inlet channel & $V_{t}$ & Total volume of the filter $\left[\mathrm{m}^{3}\right]$ \\
\hline$N u_{\text {outlet }}$ & Nusselt number of the outlet channel & $W$ & Exhaust gas molecular weight $\left[\mathrm{kg} \mathrm{kmol}^{-1}\right]$ \\
\hline$P e_{w}$ & Peclet number of wall $[-]$ & $W_{c_{(s)}}$ & Molecular weight of carbon $\left[\mathrm{kg} \mathrm{kmol}^{-1}\right]$ \\
\hline & $\mathrm{CPF}$ inlet gas pressure $[\mathrm{kPa}]$ & $W_{\mathrm{O}_{2}}$ & Molecular weight of oxygen $\left[\mathrm{kg} \mathrm{kmol}^{-1}\right]$ \\
\hline$\dot{Q}_{\text {cond,axial }}$ & Axial conduction $[\mathrm{W}]$ & $W_{\mathrm{N}_{2}}$ & Molecular weight of nitrogen dioxide $\left[\mathrm{kg} \mathrm{kmol}^{-1}\right]$ \\
\hline$\dot{Q}_{\text {cond radial }}$ & Radial conduction [W] & $\mathrm{x}$ & Diameter ratio of CPF or DOC $[-]$ \\
\hline
\end{tabular}


$Y \quad$ Mass fractions [-]

$y \quad$ Axial location $[-]$

\section{Greek Variables}

a Thermal diffusivity $\left[\mathrm{m}^{2} \mathrm{~s}^{-1}\right]$

$a_{O_{2}} \quad \mathrm{O}_{2}$ oxidation partial factor [-]

$a_{\mathrm{NO}_{2}} \quad \mathrm{NO}_{2}$ oxidation partial factor [-]

$\varepsilon_{r} \quad$ External radiation coefficient [-]

$\lambda \quad$ Effective thermal conductivity of PM cake and filter [W m ${ }^{-1} \mathrm{~K}^{-1}$ ]

$\lambda_{f} \quad$ Thermal conductivity of filter $\left[\mathrm{W} \mathrm{m}^{-1} \mathrm{~K}^{-1}\right]$

$\lambda_{s} \quad$ Thermal conductivity of PM cake $\left[\mathrm{W} \mathrm{m}^{-1} \mathrm{~K}^{-1}\right.$ ]

$\rho \quad$ Exhaust gas density $\left[\mathrm{kg} \mathrm{m}^{-3}\right]$

$\rho_{i} \quad$ Exhaust gas density in each radial zone $\left[\mathrm{kg} \mathrm{m}^{-3}\right]$

$\rho_{f} \quad$ Filter density $\left[\mathrm{kg} \mathrm{m}^{-3}\right]$

$\rho_{s} \quad$ PM cake density $\left[\mathrm{kg} \mathrm{m}^{-3}\right]$

$\sigma \quad$ Stefan-Boltzmann constant $\left[\mathrm{W} \mathrm{m}^{-2} \mathrm{~K}^{-4}\right]$

\section{Subscripts and Superscripts}

$i$ Radial direction

j Axial direction

\section{Introduction}

Diesel particulate filters play a key role in meeting current and future particulate emission standards for diesel engines. One of the disadvantages of the diesel particulate filter is the need for periodic active regeneration. Regeneration is necessary to avoid an increase in engine exhaust back pressure as the particulate matter (PM) accumulates in the filter substrate. The active regeneration oxidizes PM which reduces engine back pressure and fuel consumption caused by increased back pressure/pumping work. However, active regeneration also consumes fuel. An experimental study by Rose et al. showed that there are overall fuel consumption penalties due to the increase in back pressure and the extra fuel required for active regeneration. The results showed a $3.3 \%$ fuel penalty for a Euro 5 compliant 1.4-L turbocharged diesel engine with B10 fuel during the New European Driving Cycle [1].

The knowledge of PM mass retained as a function of time is the vital input for an effective and efficient active regeneration strategy. This is mainly because the PM loading beyond an acceptable level can lead to a damaged catalyzed particulate filter (CPF) and underloading leads to frequent regeneration events and hence excess fuel consumption and $\mathrm{CO}_{2}$ emissions. The current engine electronic control unit (ECU) controls the PM loading using an internal PM estimator model. The PM estimator relies on the calibrated engine PM maps; pressure drop across the $\mathrm{CPF}$ and temperature measurements to determine PM mass retained and regeneration frequencies [2].

Advanced regeneration strategies involve simplified CPF models that run real time within the ECU to provide more accurate feedback on current PM loading of the filter substrate. By applying simplified models that are similar to the ones used during design, development, and application of CPFs, the regeneration frequency and duration can be optimized based on vehicle operating conditions which determine engine operating conditions. This would lead to fuel consumption savings and resulting $\mathrm{CO}_{2}$ emission reductions and also a potential increase in the durability of the CPF.

The optimum regeneration frequency and duration rely on the accurate prediction of temperature distribution within the filter. Due to the heat transfer and cake PM oxidation, CPF filter temperature varies spatially (both axial and radial directions) and affects the regeneration efficiency of the filter as the PM oxidation reactions are highly temperature dependent. Hence, the accurate prediction of temperature distribution within the filter substrate will aid in the optimum regeneration frequency and duration. The prediction of temperature distribution within the filter also provides robust diagnostics capability by monitoring the CPF temperature (as a virtual sensor) at several locations within the filter. The other use of the temperature distribution prediction could be as an alternative to a conventional CFD model to calculate axial and radial temperature distribution of the substrate. This could reduce significant simulation time and resources during the design and development phase of diesel particulate filters.

Hence, the model-based approach presented in this paper would enable the use of simplified MPF models that run fast enough in the ECU to predict temperature distribution within the filter and the PM cake oxidation. This paper describes a new MPF model for modeling temperature distribution in a CPF and the local cake PM oxidation.

The overall objective of this study is to develop a computationally efficient MPF model for predicting CPF temperature distribution and PM oxidation. The model should require limited calibration effort and needs to be validated with experimental data.

To present the approach to fulfill the above objective, the paper is organized into four components of research:

1. Review the literature related to modeling of heat transfer in the CPF substrate and the PM density distribution including experimental data.

2. Develop a MPF model that is capable of simulating filter substrate temperature and PM oxidation during passive oxidation and active regeneration within the axial and radial zones of the $\mathrm{CPF}$. 
3. Develop a calibration procedure for the heat transfer within the substrate and to the ambient including PM kinetics $\left(\mathrm{NO}_{2}\right.$ - and $\mathrm{O}_{2}$-assisted $\mathrm{PM}$ oxidation) locally.

4. Calibrate the MPF model using the experimental data [3-6] to arrive at a common set of MPF model calibration parameters for all experiments.

\section{Background and Literature Review}

The literature review is organized in two parts. First, the use of simplified models (0-D and 1-D) for ECU-based controls from previous studies is explored including the heat transfer models and their assumptions. Second, the simplified multidimensional modeling efforts (2-D and 3-D) in CPF modeling were studied along with their benefits and limitations related to modeling accuracy and computational efficiency.

\subsection{CPF Models for ECU-Based Controls}

CPF models can be incorporated in the ECU to monitor and optimize CPF performance along with the engine performance. Such a CPF model for CPF regeneration was described by Kladopoulou et al. [7] using a lumped parameter model. This was a 0-D model and the simulation relied on time dependence of input parameters. The spatial dependence (axial and radial directions) was assumed to be negligible. This lumped model included an external heat transfer mechanism by considering external ambient heat transfer through convection. Subsequently, further advanced model-based control techniques were explored by many researchers to simplify conventional 1-D models for real-time ECU application with reasonable accuracy and computational speed compared to conventional map-based control approaches as presented by Rose et al. [2].

The real-time implementation of a 0 -D CPF model along with 1-D DOC model was presented by Nagar et al. [8] and showed that the 0-D CPF model was able to predict the average filter substrate temperature within $25^{\circ} \mathrm{C}$. They also highlighted the difficulty of initiating regeneration based on $\triangle P$ (difference between inlet and outlet pressure of CPF) measurement and concluded that $\mathrm{PM}$ loading provides a more reliable criterion to trigger $\mathrm{CPF}$ filter regeneration than using $\triangle P$ values. The $\mathrm{CPF}$ model by Nagar et al. assumed internal convective heat transfer from filter substrate to exhaust gas as a mechanism to dissipate the energy release during PM oxidation. However, the model ignores any conductive heat transfer within substrate.

Mulone et al. presented the 1-D CPF model for ECU application for steady-state [9] and transient operating conditions [10]. The model is based on the single channel representation of the CPF. The model was able to predict axial variation in the PM loading. However, the model ignored radial temperature gradients and the radial PM loading distribution in the CPF.
The resistance node methodology presented by Depcik et al. [11] provides a simplified and computationally efficient modeling approach to predict axial and radial temperatures of the filter. However, this model assumes uniform inlet temperature and ignores the inlet temperature variation along the radial direction of the $\mathrm{CPF}$.

\subsection{Simplified Multi-dimensional CPF Modeling}

Konstandopoulos et al. [12] developed a multichannel model using a multiphase continuum approach to simulate spatial non-uniformities in the filter (axial and radial directions). The multiphase continuum model was derived from the discrete multichannel description of the CPF. The model worked in a CFD code framework to include the partial differential equations in the CPF model. The conduction, convection, and radiation heat transfer within the filter were considered in the model. With inlet radial non-uniformities in velocity and temperature, the model showed partial regeneration of the filter. The partial regeneration mainly occurred at the periphery of the filter as the PM at the periphery of the CPF was not oxidized due to lower temperatures in this region. This continuum model is computationally expensive as it involved a system of several ordinary and partial differential equations and the equations have to be solved in a 3-D domain.

Yi [13] developed a 3-D macroscopic model for predicting PM loading within the filter. The model was based on grouping the channels with reasonably uniform inlet conditions and solving each group using 1-D model equations. This established a link between 1-D and 3-D models and reduced the complexity of detailed 3-D simulations. The model did not consider PM oxidation (passive oxidation and active regeneration) within the filter and also neglected heat losses from the substrate can of the filter. The model showed PM distribution within the filter over a period of time and also indicated that PM distribution evolves to uniform when simulated without inlet and outlet connections (uniform inlet velocity). The model showed significant non-uniform radial and axial distribution of PM when simulated with inlet and outlet connections attached to the substrate and highlighting the need for multi-dimensional analysis to determine the actual PM distribution within the filter.

\subsection{Proposed MPF Model}

The non-uniform flow and temperature at the inlet of the filter affect both axial and radial PM distribution within the filter. This would cause localized heating and excess thermal stress due to heterogeneous oxidation of PM under high temperature and a high PM loading condition. This affects the durability of CPF systems. Previous 0-D and 1-D studies ignore these effects; thus, this study focuses on developing a multi-zone modeling approach (axial and radial zones) of the CPF for ECU applications. 
The new MPF model proposed in this work is capable of predicting both temperature and PM loading distribution within the CPF in the axial and radial directions. The model considers varying $\mathrm{CPF}$ inlet temperature conditions to account for the thermal boundary layer development at the inlet of the $\mathrm{CPF}$, heat transfer within the filter, and also heat dissipation to the ambient including conduction, convection, and radiation heat transfer. PM cake oxidation by $\mathrm{O}_{2}$ and $\mathrm{NO}_{2}$ is also considered.

As will be shown later in the paper, the proposed model can predict non-uniform distribution of the filter loading and temperature within the filter substrate and it requires significantly less simulation time compared to the multi-dimensional CPF models in the literature.

\section{Experimental Data}

A 2007 inline 6-cylinder turbo charged direct-injection common rail Cummins ISL 8.9-L diesel engine rated at $272 \mathrm{~kW}$ with DOC and CPF aftertreatment devices was used for this study. The detailed specifications of the engine and aftertreatment system are shown in references [3, 4]. The brief specifications of the CPF used in this study are shown in Table 1.

Experimental data collected by Shiel et al. [3, 5] and Pidgeon et al. [4, 6] at 18 different operating conditions are used to calibrate and validate the model developed in this study. The test summary of 18 experiments ( 6 passive oxidation and 12 active regeneration experiments) used in this study is shown in reference [14]. The experiments were performed with three fuels-ULSD, B10, and B20 blends. The properties of test fuels used for the experiments are documented in references $[3,4]$. The detailed test setup, test matrix, and instrumentation are explained in reference [3] for the passive oxidation experiments and reference [4] for the active regeneration experiments.

The passive oxidation and active regeneration experiments start with $600{ }^{\circ} \mathrm{C}$ cleanup phase followed by stage 1 loading of

Table 1 Specifications of the CPF used in the experiments

\begin{tabular}{lll}
\hline & CPF & Units \\
\hline Substrate material & Cordierite & - \\
Cell geometry & Square & - \\
Diameter & 267 & $\mathrm{~mm}$ \\
Length & 305 & $\mathrm{~mm}$ \\
Cell density & $31(200)$ & cells cm \\
Cell width & 1.49 & $\left.\mathrm{~mm} \mathrm{cells} \mathrm{in.}^{-2}\right)$ \\
Wall density & 0.45 & $\mathrm{~g} \mathrm{~cm}^{-3}$ \\
Specific heat & 891 & $\mathrm{~J} \mathrm{~kg}^{-1} \mathrm{~K}^{-1}$ \\
Thermal conductivity & 0.84 & $\mathrm{~W} \mathrm{~m}^{-1} \mathrm{~K}^{-1}$ \\
\hline
\end{tabular}

filter with a DOC inlet temperature of $265 \pm 10{ }^{\circ} \mathrm{C}$ for $30 \mathrm{~min}$. Then the stage 2 loading starts and continues to achieve a target filter loading of $2.2 \pm 0.2 \mathrm{~g} / \mathrm{L}$. Upon completion of stage 2 loading, the test was continued further with the ramp up phase (RU) for $15 \mathrm{~min}$. Following the RU phase, for the passive oxidation experiments, the engine was operated at the passive oxidation test conditions (for $\mathrm{PO}-\mathrm{B} 10-16$ experiment, the $\mathrm{CPF}$ inlet conditions are temperature $408^{\circ} \mathrm{C}, 61 \mathrm{ppm} \mathrm{NO} \mathrm{N}_{2}$, $209 \mathrm{ppm} \mathrm{NOx}$, and $7.1 \% \mathrm{O}_{2}$ ) for a specified duration (43 min for PO-B10-16 experiment). For active regeneration experiments, following the RU phase, the engine was operated at an active regeneration ramp phase for $10 \mathrm{~min}$ (or until DOC inlet temperature has stabilized at $325 \pm 10^{\circ} \mathrm{C}$ ) and then the active regeneration phase for a predetermined duration $(26 \mathrm{~min}$ for AR-B10-1 experiment) at the specified CPF inlet conditions (temperature $530{ }^{\circ} \mathrm{C}, 4 \mathrm{ppm} \mathrm{NO} \mathrm{NO}_{2}, 119 \mathrm{ppm} \mathrm{NOx}$, and $7.8 \%$ $\mathrm{O}_{2}$ for AR-B10-1 experiment). Upon completion of passive oxidation phase for passive oxidation experiments and active regeneration phase for active regeneration experiments, the filter was loaded at stage 3 loading condition for $30 \mathrm{~min}$ and then the test was continued further with stage 4 loading for $60 \mathrm{~min}$. The filter was weighted at the end of each stage. The engine operating conditions for all four stages of the loading are the same.

The experimental data from these tests (temperature distribution and PM loading) are used in this study for the calibration of the internal and external heat transfer of the MPF model and also the PM kinetic parameters.

\subsection{CPF Temperature Distribution}

Having temperature distribution data is critical for this study to validate the MPF model since predicting temperature distribution within the $\mathrm{CPF}$ is one major contribution from this study. The experimental temperature distribution data were collected from references $[5,6]$. For each of the 18 experiments in this study, temperature distribution within the CPF was measured using 16 ungrounded K-type thermocouples to determine temperature distribution within the filter during each test. These data were used for the heat transfer model calibration and validation of the MPF model simulation data. The CPF thermocouple layout and specifications of the thermocouples are shown in references [5, 6].

The CPF thermocouples were placed at four axial locations (at a distance of 32, 98,152, and $273 \mathrm{~mm}$, respectively, from the end of the filter) and four radial locations (at diameters of 0,110,190, and $244 \mathrm{~mm}$ ). The temperature distribution measured by thermocouples $(\mathrm{C} 1-\mathrm{C} 16)$ for AR-B10-1 experiment at $5.63 \mathrm{~h}$ (15 min after fuel dosing) is shown in Fig. 1. Figure 2 shows the radial temperature distribution measured by thermocouples $\mathrm{C} 1-\mathrm{C} 4$ during the entire test duration.

From Figs. 1 and 2, the following trends are observed. The temperatures are varying in both the axial and radial directions. 


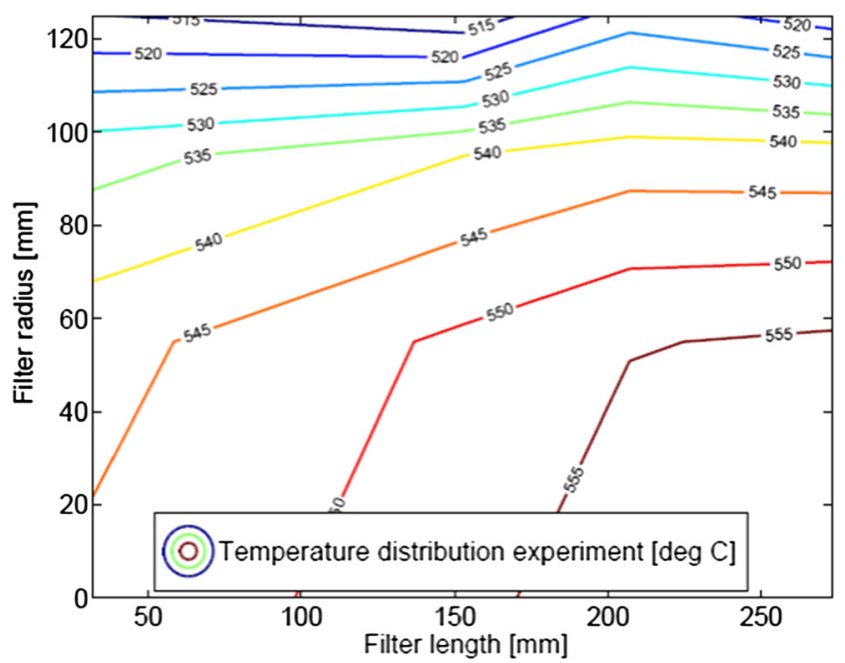

Fig. 1 Measured $\mathrm{CPF}$ temperature distribution during AR-B10-1 experiment at $5.63 \mathrm{~h}$ (15 min after fuel dosing)

The radial variation of temperature is comparatively higher (up to $40{ }^{\circ} \mathrm{C}$ ) than the axial variation in temperature (up to $12{ }^{\circ} \mathrm{C}$ ). The radially decreasing temperature is attributed to external ambient heat transfer of the filter and inlet flow/temperature maldistribution, and the axially increasing temperature is attributed to the oxidation of PM within the filter during active regeneration along with the heat transfer. Without the PM oxidation, the temperature would drop axially due to heat transfer.

\section{Model Development}

\subsection{Overview}

The MPF model presented in this paper is an extension of the 0-D lumped models developed by Kladopoulou et al. [7] and Johnson et al. [15]. The model development presented in this

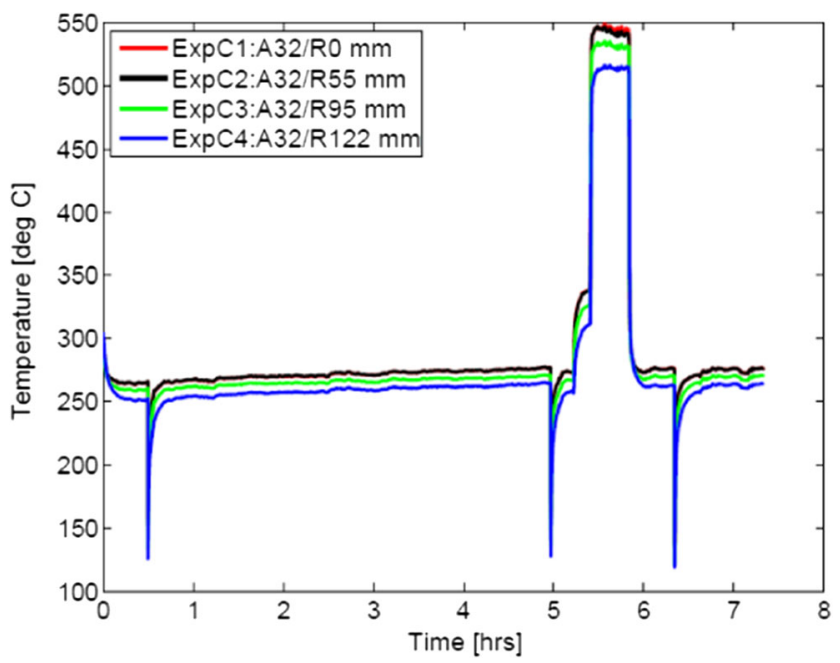

Fig. 2 Measured CPF temperature distribution during AR-B10-1 experiment for thermocouples $\mathrm{C} 1-\mathrm{C} 4$ paper is based on the resistance node methodology presented by Depcik et al. [11]. In the MPF model, the CPF is modeled as a user configurable number of axial and radial zones as shown in Fig. 3.

The filter and gas energy equation is employed at each zone. The energy equation considers the heat transfer within the filter and external to the filter through convection, conduction, and radiation heat transfer modes. The PM oxidation model is also applied in each zone and the model considers PM oxidation by thermal $\left(\mathrm{O}_{2}\right)$ - and $\mathrm{NO}_{2}$-assisted mechanisms using inlet $\mathrm{O}_{2}$ and $\mathrm{NO}_{2}$ concentrations. The model also takes into account the inlet temperature distribution assuming the fully developed boundary layer at the inlet of the CPF. The coefficients used for generating the temperature profile at the inlet of the filter are explained later in the paper. The model outputs are temperature distribution within the filter substrate, total PM mass retained, and PM loading distribution within the filter. The inlet channel, outlet channel, PM cake layer, and substrate wall velocity equations are also included in the model to allow future work for predicting species concentration within the filter substrate. The model assumptions are outlined as follows:

1. The inlet PM deposits uniformly over the entire volume of the filter substrate and all the PM deposits as a cake.

2. The PM inlet rate into the each zone is assumed to be the ratio of volume of each zone to the total volume of the filter. In other words, no maldistribution of inlet PM is considered.

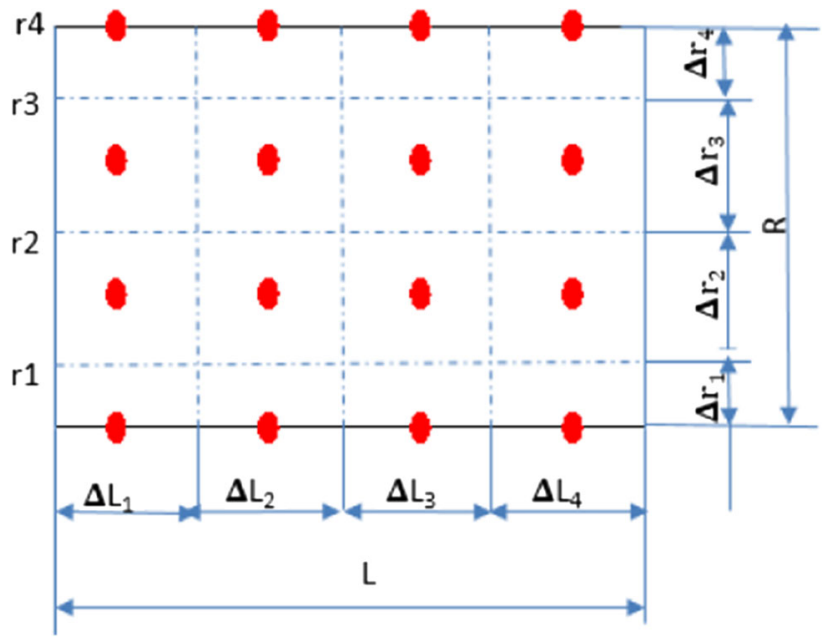

$\mathrm{R}=$ Radius of the filter

$L=$ Length of the filter

$\mathrm{r} 1, \mathrm{r} 2, \mathrm{r} 3$ and $\mathrm{r} 4=$ Radial distance of each zone from centerline

$\Delta \mathrm{r} 1, \Delta \mathrm{r} 2, \Delta \mathrm{r} 3$ and $\Delta \mathrm{r} 4=$ Effective zone radius

$\Delta \mathrm{L} 1, \Delta \mathrm{L} 2, \Delta \mathrm{L} 3$ and $\Delta \mathrm{L} 4=$ Effective zone length

Fig. $34 \times 4$ Multi-zone CPF model schematic. $R$ radius of the filter; $L$ length of the filter; $r 1, r 2, r 3$, and $r 4$ radial distance of each zone from centerline; $\Delta r 1, \Delta r 2, \Delta r 3$, and $\Delta r 4$ effective zone radius; and $\Delta L 1, \Delta L 2$, $\Delta L 3$, and $\Delta L 4$ effective zone length 
3. Species concentrations $\left(\mathrm{O}_{2}\right.$ and $\left.\mathrm{NO}_{2}\right)$ are assumed to be uniform in each zone of the filter and are equal to inlet concentrations.

4. Back diffusion of $\mathrm{NO}_{2}$ due to the catalyst wash coat is not considered.

5. Gaseous hydrocarbon oxidation within $\mathrm{CPF}$ is not considered.

6. PM cake layer and substrate wall are at the same temperature. In other words, no temperature gradient across the PM cake layer and substrate wall is considered.

7. A fully developed boundary layer exists at the inlet of the CPF.

8. The exhaust gas mixture is assumed to be an ideal gas.

9. The exhaust gas has the same properties as air at $1 \mathrm{~atm}$ pressure. Properties are considered as a function of temperature. CPF inlet species concentrations $\left(\mathrm{CO}_{2}, \mathrm{O}_{2}, \mathrm{~N}_{2}\right.$, and $\mathrm{H}_{2} \mathrm{O}$ ) are used for the calculation of molecular weight of the exhaust gas.

\subsection{Discretization}

Discretization of the filter volume is done in both the axial $(\Delta L)$ and radial directions $(\boldsymbol{\Delta} r)$ as shown in Fig. 4. Figure 4 shows the physical representation of the CPF channels with uniform deposition of PM in the cake layer along the walls of inlet channel. In the MPF model, the full volume of the filter is discretized into a user-configurable number of axial and radial zones. Each zone is comprised of multiple inlet and outlet channels. The schematic representation of the channel geometry for each zone is shown in Fig. 5. Each zone consists of the filter substrate, PM cake, and empty volume for inlet and outlet channels. The multi-zone model discretization equations are presented in Appendix A.

\subsection{Filter Temperature Equations}

The energy stored in the filter is due to the (a) heat conduction along the length of the filter $\left(\dot{Q}_{\text {cond.radial }}\right)$, (b) heat conduction

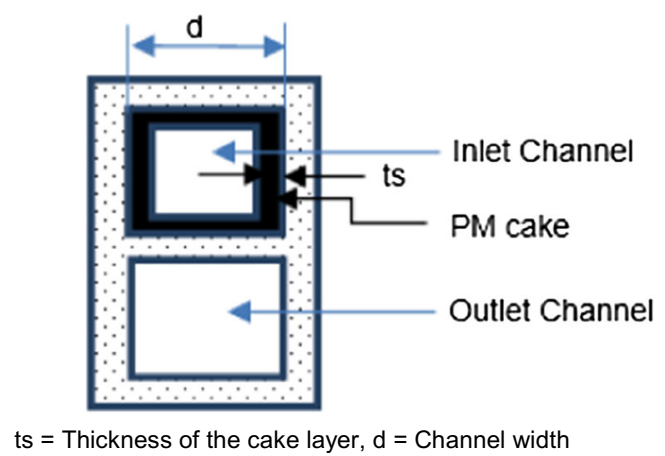

Fig. 4 Schematic of the CPF channel geometry with the PM cake layer $t s=$ thickness of the cake layer, $d=$ channel width

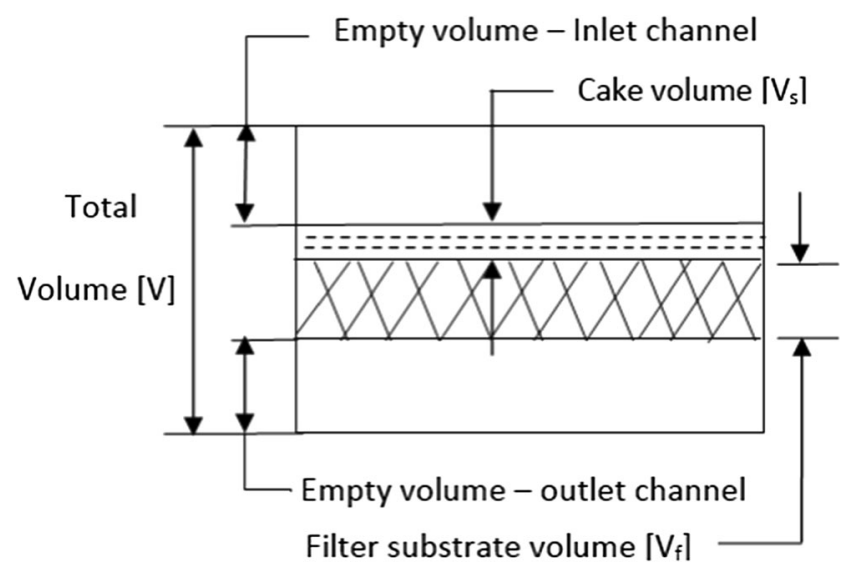

Fig. 5 Schematic for a zone of the MPF model

along the radial direction of the filter $\left(\dot{Q}_{\text {cond.radial }}\right)$, (c) convection between the filter and the channel gas $\left(\dot{Q}_{\text {conv }}\right)$, (d) energy released during oxidation of the PM cake $\left(\dot{Q}_{\text {reac }}\right)$, and (e) heat transfer due to radiation exchange between channel surfaces $\left(\dot{Q}_{\mathrm{rad}}\right)$. The energy flow through the wall is neglected as there will be no distinction between inlet and outlet channels in the MPF model in this work. Hence, the energy equation for the filter is as follows:

$$
\begin{aligned}
& \left(\rho_{s} c_{s} V s_{i, j}+\rho_{f} c_{f} V_{f_{i, j}}\right) \quad \frac{d T f_{i, j}}{d t}= \\
& \dot{Q}_{\text {cond.axial }}+\dot{Q}_{\text {cond.radial }}+\dot{Q}_{\text {conv }}+\dot{Q}_{\text {reac }}+\dot{Q}_{\text {rad }}
\end{aligned}
$$

where $T f$ is the filter substrate temperature.

The detailed formulation for the terms used in Eq. (1) is explained in Appendix A.

The convection heat transfer between the filter substrate and the channel gas is calculated using the following equations $[11,19]$ :

$\dot{Q}_{\text {conv }}=h_{g} A s_{i, j}\left(T_{i, j}-T f_{i, j}\right)$

The convective heat transfer coefficient $\left(h_{g}\right)$ is calculated using the fully developed Nusselt number correlation based on the flow Peclet and Reynolds number through the wall for a square channel configuration. Depcik et al. [16] determined Nusselt number correlations from the historical references for Prandtl number of 0.72 (approximately air). Recently, Bissett et al. [17] and Kostoglou et al. [18] derived Nusselt number correlations for wall-flow monoliths for the parameter range applicable for the diesel particulate application. From reference [17], the polynomial approximations of Nusselt numbers for $R e_{w}<3$ are given as

$N u_{\text {inlet }}=2.98+0.60 P e_{w}-0.143 R e_{w}$

$N u_{\text {outlet }}=2.98-0.40 P e_{w}$

In the MPF model, as there is no distinction between inlet and outlet channel, the average Nusselt number is used for 
computing the heat transfer coefficient for the combined inlet and outlet channel and it is given as

$N u_{\text {avg }}=N u_{\text {inlet }}+N u_{\text {outlet }}=\frac{h_{g} d}{k_{g}}$

where

$N u_{\text {avg }} \quad$ Average Nusselt number of the inlet and outlet channel

$N u_{\text {inlet }} \quad$ Nusselt number of the inlet channel

$N u_{\text {outlet }} \quad$ Nusselt number of the outlet channel

$k_{g} \quad$ Thermal conductivity of channel gas

$P e_{w} \quad$ Peclet number of wall

$R e_{w} \quad$ Reynolds number of wall

$A s_{i, j} \quad$ Combined surface area of inlet and outlet channels.

\subsection{PM Oxidation}

The PM oxidation equations include PM oxidation by thermal $\left(\mathrm{O}_{2}\right)$ - and $\mathrm{NO}_{2}$-assisted reactions. The total rate of PM mass oxidation in the cake due to thermal- and $\mathrm{NO}_{2}$-assisted oxidation is equal to [16],

Total rate of PM oxidation

$=$ PM oxidation by thermal $\left(\mathrm{O}_{2}\right)$

+ PM oxidation by $\mathrm{NO}_{2}$ assisted

$\frac{d\left(m s_{i, j}\right)}{d t}=-\frac{S_{p} \rho_{i, j} Y_{i, j} O_{2} k_{O_{2}} W_{c}}{\alpha_{O_{2}} W_{O_{2}} \rho_{s}} m s_{i, j}-\frac{S_{p} \rho_{i, j} Y_{i, j N O_{2}} k_{N_{2}} W_{c}}{\alpha_{N O_{2}} W_{N O_{2}} \rho_{s}} m s_{i, j}$

where

$\frac{d\left(m s_{i, j}\right)}{d t}=$ Rate of PM mass oxidized in each zone

In Eq. (5), the pressure term for computing the exhaust gas density $\left(\rho_{i, j}\right)$ is assumed to be constant.

The details of formulation for the terms used in Eq. (5) is explained in Appendix A.

\subsection{Velocity Equations}

Using average gas velocity equations for the entire filter substrate from reference [11], the average velocity through the PM cake $\left(u_{s_{i}}\right)$ and wall layers $\left(u_{w_{i}}\right)$ for each radial zone is

$u_{s_{i}}=\frac{\dot{m}_{i, j}}{4 \rho_{i, j} \frac{N c_{i}}{2}\left(d-2 \cdot \overline{t s_{i}}\right) L_{t}}$

$u_{w_{i}}=\frac{u_{s_{i}\left(d-2 . \overline{s_{i}}\right)}}{d}$
The average velocity through the inlet channel $\left(u_{I}\right)$ and outlet channel $\left(u_{I I}\right)$ for each radial zone can be determined as

$\left.u_{I}\right|_{i, j}=\left.u_{I}\right|_{j-1}-\frac{4 u_{s i}}{\mathrm{~d}-2 . \overline{t s_{i}}} \Delta L_{j-1}$

$\left.u_{I I}\right|_{i, j}=\left.u_{I I}\right|_{j-1}+\frac{4 u_{w i}}{d} \Delta L_{j-1}$

The detailed formulation of Eqs. (6) to (9) are explained in Appendix A.

\subsection{Temperature Distribution at Filter Inlet}

The radial temperature distribution at the inlet of the filter is due to the thermal boundary layer development as explained in references [12, 19-21]. In order to account for the thermal boundary layer development, the empirical temperature factor profile is determined by analyzing experimental data from the 18 runs.

The temperature profile at the inlet of the CPF is not constant across the radial direction for the data in Figs. 1 and 2. This is mainly because of the thermal boundary layer development in the upstream of exhaust pipes and the DOC. The thermal boundary layer develops when the exterior surface of the pipe is exposed to a different temperature than the fluid flowing through the pipe. If the air temperature of outer surface is lower than the exhaust gas temperature, then the temperature of the exhaust gas in contact with the inner surface decreases and causes a subsequent drop in temperature of the exhaust gas in other regions of the pipe. This leads to the development of thermal boundary layer (similar to velocity boundary layer).

For a fully developed flow, the temperature factor shown below is constant across the length (temperature profile is constant). Hence, from reference [19],

$\frac{\partial}{\partial x}\left[\frac{T_{s}(y)-T(r, y)}{T_{s}(y)-T_{m}(y)}\right]=0$

Temperature Factor $=\frac{T_{s}-T_{r}}{T_{s}-T_{m}}=C$

where

$T_{m} \quad$ Mean exhaust gas temperature

$T_{\mathrm{S}} \quad$ Wall inner surface temperature

$T_{r} \quad$ Temperature at a given radial location

$y \quad$ Axial location.

For this modeling work, the temperature factor at the inlet of $\mathrm{CPF}$ was determined by analyzing the $\mathrm{C} 1, \mathrm{C} 2, \mathrm{C} 3$, and $\mathrm{C} 4$ thermocouple measurements. Figure 6 shows the temperature 


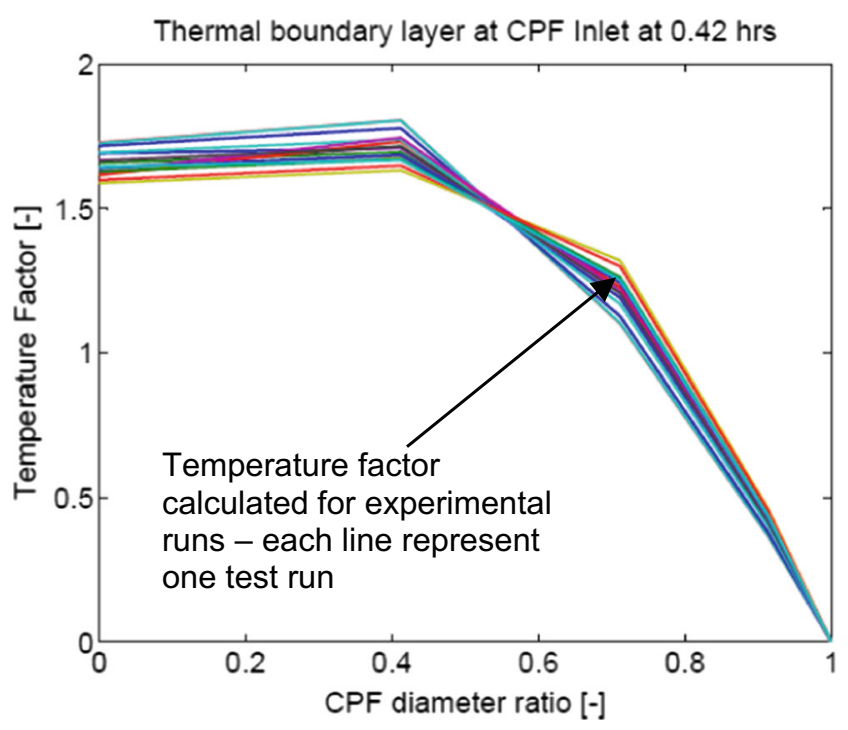

Fig. 6 Temperature factor profile at filter inlet

factor calculated using Eq. (11) for all 18 runs at $0.42 \mathrm{~h}$. The horizontal axis is the CPF diameter ratio, 0 means center of the filter and 1.0 means outer diameter of the filter. The 3rd-order polynomial equation was used as the curve fit to represent the temperature factor for a given diameter ratio of the $\mathrm{CPF}$ and is given by

Temperature Factor $(\mathrm{x})=-2.493 \mathrm{x}^{3}$

$$
\begin{aligned}
& +1.0585 x^{2}-0.3285 x \\
& +1.7631
\end{aligned}
$$

where $x$ is the diameter ratio at a given location.

The diameter ratio is the ratio of CPF diameter at a given measurement location to the maximum $\mathrm{CPF}$ diameter. From Fig. 6, the temperature factor is almost constant up to CPF diameter ratio of 0.4 (indicating uniform temperature) and drops to 0 value (minimum temperature) at the CPF diameter ratio of 1.0 (outer radius of the filter). The maximum gradient in the temperature factor is observed at the CPF diameter ratio of 0.8 to 1.0 , showing that $50 \%$ of the radial temperature reduction is in the $20 \%$ of the filter section closest to the outer radius of the filter. From Appendix B, the minimum substrate temperature at the outer surface $(R=133 \mathrm{~mm})$ is $4.3 \%$ lower than mean substrate temperature at the inlet $\left(\frac{T_{m}}{T_{s}}=1.043\right)$.

The detailed procedure for developing the thermal boundary layer temperature factor and other coefficients used in the MPF model are explained in Appendix B. Using Eqs. $(11,12)$ and knowing the temperature at one radial location/zone of the $\mathrm{CPF}$ inlet, the temperatures at the other radial locations can be determined. The MPF model uses one CPF inlet temperature sensor data $\left(\mathrm{T}_{\text {in }}\right)$ to develop thermal boundary layer profile for the remaining zones at the $\mathrm{CPF}$ inlet.

\subsection{Numerical Solver}

The model formulation involves simulation of the time-varying temperature within the $\mathrm{CPF}$ from node to node. Hence, an explicit solver scheme was used to determine the temperature at each time step. The explicit solver estimates the filter substrate temperature for a time step $(t)$ using temperature values from the previous time step $(t-1)$. This approach is relatively simple to setup and program. However, $\Delta t$ must be less than the limit imposed by stability constraints $[19,22]$ The temperature for the new time step with the explicit solver method can be expressed mathematically as (for $i=2$ to imax and $j=1$ to jmax)

Temp _ filter_new ${ }_{i, j}=$ Temp _ filter_old ${ }_{i, j}+\cdots$
$+\frac{\dot{Q}_{\text {cond.axial }}+\dot{Q}_{\text {cond.radial }}+\dot{Q}_{\text {conv }}+\dot{Q}_{\text {reac }}+\dot{Q}_{\text {rad }}}{\left(\rho_{s} c_{s} V s_{i, j}+\rho_{f} c_{f} V f_{i, j}\right)} \Delta t$

where

$\Delta t$ is the time step for the solver.

The explicit method is easy to use, but it is not unconditionally stable and the largest permissible value of $\Delta t$ is limited by the stability criterion. For larger time steps, the explicit method oscillates widely and diverges from the actual solution. In general, the stability criterion is satisfied when the primary coefficients of all temperature terms in the Eq. (13) are greater than or equal to zero for all nodes [19]. Since the time step for each term is different, the practical approach to this problem is to use the most restrictive time step. From reference [19], the 1D convection problem for a plane wall, the time step is expressed as

$\Delta t \leq \frac{\Delta x^{2}}{2 \alpha\left(1+\frac{h \Delta x}{k}\right)}$

where, $\Delta x$ is the discretization length (minimum of $\Delta L$ or $\Delta r$ ), $\alpha$ is the thermal diffusivity of the filter substrate. However, considering the heat transfer between filter and channel gas, $\alpha$ is minimum at the gas side and hence

$\alpha=\frac{k_{g}}{\rho c_{p}}$

where

$k_{g} \quad$ Thermal conductivity of exhaust gas

$\rho \quad$ Density of exhaust gas

$c_{p} \quad$ Specific heat capacity of exhaust gas

$h=h_{g} \quad$ Convective heat transfer between filter substrate and channel gas.

Using the Eqs. (14) and (15), the initial values of time step can be determined. The MPF model includes conduction, convection, and radiation terms together. By iteration from the above initial guess, the stable time step of $0.01 \mathrm{~s}$ was determined to work for up to a $20 \times 20$ multi-zone formulation in this work. 


\section{Model Calibration}

\subsection{Inputs and Outputs}

The MPF model has 4 sets of input variables, 15 constants, and 7 calibration parameters. The model needs to be parameterized in order to simulate the temperature and PM mass loading distribution within the filter substrate. The input variables include

1) Instantaneous exhaust mass flow rate $(\dot{m})$

2) $\mathrm{CPF}$ inlet concentrations $\left(\mathrm{C}_{\mathrm{PM}}, \mathrm{C}_{\mathrm{NO} 2}\right.$, and $\left.\mathrm{C}_{\mathrm{O} 2}\right)$

3) $\mathrm{CPF}$ inlet temperature $\left(T_{\text {in }}\right)$

4) $\mathrm{CPF}$ inlet gas pressure $\left(P_{\text {in }}\right)$.

The constants of the MPF model are listed in Table 2. The model constants $\mathrm{C} 1$ to $\mathrm{C} 6$ were determined from the thermal boundary layer formulation as explained in Appendix B. There are two groups of unknown calibration parameters in the MPF model. These two groups include (i) PM oxidation parameters and (ii) heat transfer coefficients. These two groups of parameters are determined by using optimization techniques and the experimental data.

\subsection{Calibration Process}

For the model calibration and results presented in this work, the $10 \times 10$ MPF model was used which runs about 12 times faster than real time on a laptop with 12-GB RAM, 64-bit and inter core $\mathrm{i} 7$ processor. However, the optimum number of zones for an ECU application can be determined by running

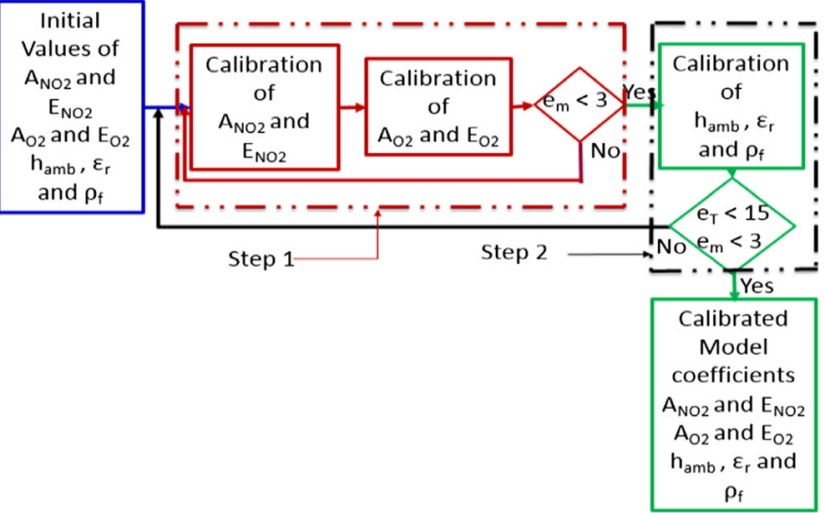

Fig. 7 Model calibration flow chart

the model at different levels of discretization (axial and radial zones). This discretization study along with the detailed model validation is ongoing work and will be covered in the next research paper.

The overall objective of the calibration process was to simulate the axial and radial PM loading distribution to agree with the total experimental PM mass retained within $3 \mathrm{~g}$. This was achieved by the two-step calibration process shown in Fig. 7.

1) Calibration of PM oxidation: $\mathrm{PM}$ kinetic parameters $\left(A_{\mathrm{NO} 2}, E_{\mathrm{NO} 2}, A_{\mathrm{O} 2}\right.$, and $\left.E_{\mathrm{O} 2}\right)$ are determined in this step. The calibration of PM kinetic parameters from the engine experiments are preferred over synthetic gas-based lab reactor experiments because the engine experiments provide representative $\mathrm{PM}$ composition, residence time, and operating temperatures of the filter for calibration. Hence, the PM kinetic parameters determined from the engine experiments can be directly used in the MPF model.

Table 2 MPF model constants

\begin{tabular}{llll}
\hline Symbol & Description & Units & Values \\
\hline $\mathrm{F}$ & Radiation view factor & {$[-]$} & 0.011 \\
$\mathrm{C} 1$ & DOC radial temperature distribution factor 1 & {$[-]$} & -2.493 \\
$\mathrm{C} 2$ & DOC radial temperature distribution factor 2 & {$[-]$} & 1.0585 \\
$\mathrm{C} 3$ & DOC radial temperature distribution factor 3 & {$[-]$} & -0.3285 \\
$\mathrm{C} 4$ & DOC radial temperature distribution factor 4 & {$[-]$} & 1.7631 \\
$\mathrm{C} 5$ & DOC mean to surface temperature ratio & {$[-]$} & 1.0425 \\
$\mathrm{C} 6$ & DOC temperature sensor offset & {$[-]$} & $0.0273 *$ Tin-2.4996 \\
$\rho_{\mathrm{pm}}$ & PM density & $\mathrm{kg} \mathrm{m}^{-3}$ & 104 \\
$\mathrm{Sp}$ & Specific surface area of PM & $\mathrm{m}^{-1}$ & $5.5 \times 10^{7}$ \\
$\mathrm{C} p_{\mathrm{air}}$ & Specific heat of air & $\mathrm{J} \mathrm{kg}^{-1} \mathrm{~K}^{-1}$ & $\mathrm{Using}$ Eq. $(66)$ \\
$\mu$ & Dynamic viscosity of air & $\mathrm{N} \mathrm{s} \mathrm{m}^{-2}$ & Using Eq. $(67)$ \\
$\lambda_{f}$ & Thermal conductivity of substrate wall & $\mathrm{W} \mathrm{m}^{-1} \mathrm{~K}^{-1}$ & 1 \\
$\lambda_{p}$ & Thermal conductivity of PM cake layer & $\mathrm{W} \mathrm{m}^{-1} \mathrm{~K}^{-1}$ & 2.1 \\
$\alpha_{\mathrm{O} 2}$ & $\mathrm{O}_{2}$ combustion partial factor & {$[-]$} & 0.8 \\
$\alpha_{\mathrm{NO} 2}$ & NO ${ }_{2}$ combustion partial factor & {$[-]$} & 1.75 \\
\hline
\end{tabular}


The objective of the first step is to minimize the error between the simulation and the total experimental PM mass retained.

2) Calibration of heat transfer coefficients: convective and radiation heat transfer coefficients $\left(h_{\mathrm{amb}}\right.$ and $\left.\varepsilon_{r}\right)$ are determined from this step. In addition, the filter substrate density $\left(\rho_{f}\right)$ is found. The substrate density along with other thermophysical properties (thermal conductivity, substrate density, and PM density) of the filter changes during the filter loading. Hence, in order to simulate the change in thermophysical properties of the filter, the filter substrate density is also considered as the one of the calibration variables in the MPF model. Depcik et al. [11] showed in his model calibration efforts that the model accuracy could be improved during temperature rise portion of the experiment by optimizing the filter substrate density. The objective of this step is to minimize the RMS temperature error between the simulation and the experimental data measured by the $16 \mathrm{CPF}$ thermocouples during the stage 1 and 2 loading phases of the experiments.

The calibration process starts with the initial assumption of calibration parameters. The initial values of the calibration parameters were determined from the references $[11,14,23$, 24]. All 18 runs are simulated and the results are compared with the experimental data. To improve the model accuracy, the calibration process is repeated if the PM mass loading error exceeds $3 \mathrm{~g}$ and the RMS temperature distribution error exceeds $15{ }^{\circ} \mathrm{C}$. Details about the calibration process for the two steps are explained next.

\subsubsection{Step 1: PM Kinetics Calibration Procedure}

The objective of the PM kinetics calibration procedure is to simulate the experimental total PM mass retained within the filter at each of the four stages of loading. This was achieved by determining $\mathrm{NO}_{2}$-assisted $\mathrm{PM}$ oxidation kinetic parameters $\left(A_{\mathrm{NO} 2}\right.$ and $\left.E_{\mathrm{NO} 2}\right)$ and thermal $\left(\mathrm{O}_{2}\right)$-assisted PM oxidation kinetic parameters $\left(A_{\mathrm{O} 2}\right.$ and $\left.E_{\mathrm{O} 2}\right)$ from the experimental runs (passive oxidation and active regeneration). The error term $e_{m}$ in Fig. 7 represents the error between simulated and experimental PM mass retained at each of the four stages of loading.
The tasks involved in the PM kinetics calibration are the following:

1. Determine the $\mathrm{NO}_{2}$-assisted PM kinetics $\left(A_{\mathrm{NO} 2}\right.$ and $\left.E_{\mathrm{NO} 2}\right)$ from the passive oxidation experiments keeping other parameters constant. Optimization is done in Matlab ${ }^{\circledR}$ using Nelder-Mead Simplex method [25]. Matlab function fminsearch is used to minimize the error between MPF model simulation and the experimental PM mass retained. The error value of $1 \mathrm{~g}$ is used as the target for the Simulink design optimization at the end of each of the stages of loading.

2. Use the $\mathrm{NO}_{2}$-assisted PM kinetics (from task 1) to determine the thermal $\left(\mathrm{O}_{2}\right)$-assisted PM kinetics from the active regeneration experiments keeping other parameters constant in the model.

3. From the PM kinetics determined from tasks 1 and 2, use the Arrhenius plots to determine the optimum PM kinetic parameters for each type of fuel.

4. From tasks 1,2 , and 3, determine one set of PM kinetic calibration parameters $\left(A_{\mathrm{NO} 2}, E_{\mathrm{NO} 2}, A_{\mathrm{O} 2}\right.$, and $\left.E_{\mathrm{O} 2}\right)$ for each type of fuel (ULSD, B10, and B20)

\subsubsection{Step 2: Heat Transfer Coefficients Calibration}

Similar to step 1, Nelder-Mead Simplex optimization method [24] is used to calibrate the heat transfer coefficients in the MPF model. The heat transfer coefficients and filter density values are varied keeping all other parameters constant in the model. The objective of the optimization routine is to minimize the RMS temperature error between the simulation and the experimental temperature data measured by the 16 thermocouples during stages 1 and 2 of the loading phase of the experiment. The RMS error of $2{ }^{\circ} \mathrm{C}$ is used as the target for optimization.

The resulting model parameters from the 2-step calibration procedure are shown in Tables 3 and 4. Simulation results and experimental validation of the MPF model with calibrated parameters are provided in the next section.

Table 5 shows the standard deviation (1 sigma) of the activation energy and pre-exponential between the experiments

Table 3 Calibrated parameters of the MPF model for PM kinetics for three different fuels

\begin{tabular}{|c|c|c|c|c|c|c|}
\hline PM oxidation & Symbol & Description & Units & ULSD & $\mathrm{B} 10$ & $\mathrm{~B} 20$ \\
\hline \multirow[t]{2}{*}{$\mathrm{NO}_{2}$-assisted } & $A_{\mathrm{NO} 2}$ & Pre-exponential for $\mathrm{NO}_{2}$-assisted $\mathrm{PM}$ oxidation & $\mathrm{m} \mathrm{K}^{-1} \mathrm{~s}^{-1}$ & 0.0088 & 0.0083 & 0.0085 \\
\hline & $E_{\mathrm{NO} 2}$ & Activation energy for $\mathrm{NO}_{2}$-assisted PM oxidation & $\mathrm{kJ} \mathrm{gmol}^{-1}$ & 60.8 & 64.1 & 63.1 \\
\hline \multirow[t]{2}{*}{ Thermal $\left(\mathrm{O}_{2}\right)$} & $A_{\mathrm{O} 2}$ & Pre-exponential for thermal $\left(\mathrm{O}_{2}\right)$ PM oxidation & $\mathrm{m} \mathrm{K}^{-1} \mathrm{~s}^{-1}$ & 0.982 & 1.004 & 1.029 \\
\hline & $E_{\mathrm{O} 2}$ & Activation energy for thermal $\left(\mathrm{O}_{2}\right)$ PM oxidation & $\mathrm{kJ} \mathrm{gmol}^{-1}$ & 158.1 & 151.8 & 148.9 \\
\hline
\end{tabular}


Table 4 Calibrated heat transfer coefficients and filter density for the MPF model

\begin{tabular}{llll}
\hline Symbol & Description & Units & Values \\
\hline $\mathrm{h}_{\mathrm{amb}}$ & Convection heat transfer coefficient & $\mathrm{W} \mathrm{m}^{-2} \mathrm{~K}^{-1}$ & 8.1 \\
$\varepsilon_{\mathrm{r}}$ & External radiation coefficient & {$[-]$} & 0.16 \\
$\rho_{\text {filter }}$ & Filter density & $\mathrm{kg} \mathrm{m}^{-3}$ & 449 \\
\hline
\end{tabular}

for all three types of fuel used based on an analysis of the Arrhenius plots of the data.

\section{Results and Discussion}

Using the single set of calibration parameters (Tables 3 and 4) determined from the calibration process, the MPF model simulations of one passive oxidation (PO-B10-16) and one active regeneration (AR-B10-1) experiment were studied. The results are presented in the following section.

\subsection{Temperature Distribution}

Figure 8 shows the radial temperature distribution of the POB10-16 experiment measured by $\mathrm{C} 13-\mathrm{C} 16$ thermocouples (shown as continuous line) and the temperatures simulated by the MPF model (shown as dotted line) at the outlet of the filter (273 mm from the filter inlet). As shown in Fig. 8, the MPF model simulation closely follows the experimental data (within $5 \mathrm{C}$ excluding the temperature spikes related to experimental procedure and transition phases of moving in and out of PO phase of the experiment) during the entire experiment.

Figure 9 shows the axial temperature distribution of the thermocouple measurements at the center of the filter $(\mathrm{R}=$ $0 \mathrm{~mm}$ ). As shown in Fig. 9, the simulation and experimental data shows that the temperature of the substrate is nearly constant during the experiment along the length of the filter (axially 32, 153, 207 and $273 \mathrm{~mm}$ from the front of the filter).

Figure 10 shows the temperature distribution measured by all 16 thermocouples and temperatures simulated by the MPF model at $4.73 \mathrm{~h} \mathrm{(15} \mathrm{min} \mathrm{after} \mathrm{switching} \mathrm{to} \mathrm{passive} \mathrm{oxidation}$ engine operating condition). The engine operating condition at $4.73 \mathrm{~h}$ is chosen to compare the model predictability at high temperature regions of the experiment. From Fig. 10, it is

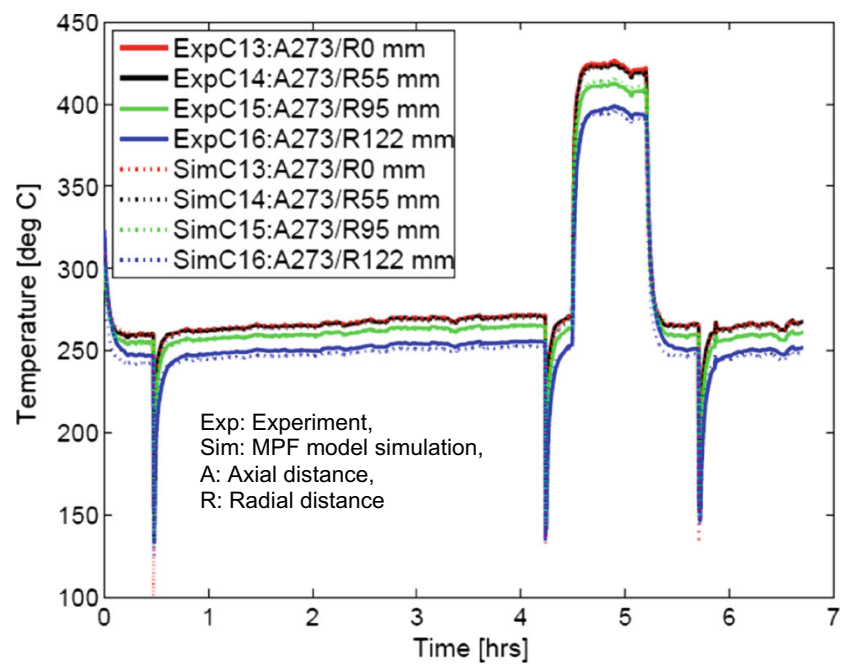

Fig. 8 Radial temperature distribution at filter outlet (PO-B10-16 experiment)

evident that the MPF model follows the experimental data. The maximum absolute temperature difference between the experimental and simulation data is $5{ }^{\circ} \mathrm{C}$. From Fig. 10, the filter substrate temperatures for radius less than $80 \mathrm{~mm}$ are almost same. A slight temperature increase $\left(1-2{ }^{\circ} \mathrm{C}\right)$ in axial direction is due to the local PM oxidation. The substrate temperature close to the wall shows a slight decrease in temperature due to the dominant convection and radiative heat loss to the ambient compared to the local PM oxidation.

Figure 11 shows the radial temperature distribution for the AR-B10-1 experiment as measured by the C13-C16 thermocouples and the temperatures simulated by the MPF model at the outlet of the filter ( $273 \mathrm{~mm}$ from the filter inlet). The MPF model is within $-24 /+6^{\circ} \mathrm{C}$ to the experimental data (excluding the temperature spikes related to the experimental procedure and the transition phase of moving in and out of AR phase of the experiment). The temperatures close to the outer surface of the filter substrate $(R=122 \mathrm{~mm})$ showed the maximum temperature deviation during the active regeneration phase of the experiment compared to the other locations of the filter substrate. The temperature simulated by the MPF model during loading ( 0 to $5.0 \mathrm{~h}$ ) and post loading ( 6.3 to $7.3 \mathrm{~h}$ ) phase of the experiment is within $\left(7^{\circ} \mathrm{C}\right)$ to the experimental data.

Figure 12 shows the axial temperature distribution of the thermocouple measurements at the center of the filter $(R=$ $0 \mathrm{~mm}$ ). As seen from Fig. 12, the temperature stays constant

Table 5 PM kinetics parameters standard deviation summary between runs

\begin{tabular}{|c|c|c|c|c|c|c|}
\hline PM oxidation & Symbol & Description & Units & ULSD (\%) & B10 (\%) & $\mathrm{B} 20$ \\
\hline \multirow[t]{2}{*}{ NO2 assisted } & $A_{\mathrm{NO} 2}$ & Pre-exponential for $\mathrm{NO}_{2}$-assisted PM oxidation & $\mathrm{m} \mathrm{K}^{-1} \mathrm{~s}^{-1}$ & 3.8 & 0.6 & NA \\
\hline & $E_{\mathrm{NO} 2}$ & Activation energy for $\mathrm{NO}_{2}$-assisted PM oxidation & $\mathrm{kJ} \mathrm{mol}^{-1}$ & 1.1 & 1.2 & NA \\
\hline \multirow[t]{2}{*}{ Thermal (O2) } & $A_{\mathrm{O} 2}$ & Pre-exponential for thermal $\left(\mathrm{O}_{2}\right)$ PM oxidation & $\mathrm{m} \mathrm{K}^{-1} \mathrm{~s}^{-1}$ & 1.4 & 2.5 & $4.5 \%$ \\
\hline & $E_{\mathrm{O} 2}$ & Activation energy for thermal $\left(\mathrm{O}_{2}\right)$ PM oxidation & $\mathrm{kJ} \mathrm{mol}^{-1}$ & 0.8 & 0.2 & $0.9 \%$ \\
\hline
\end{tabular}




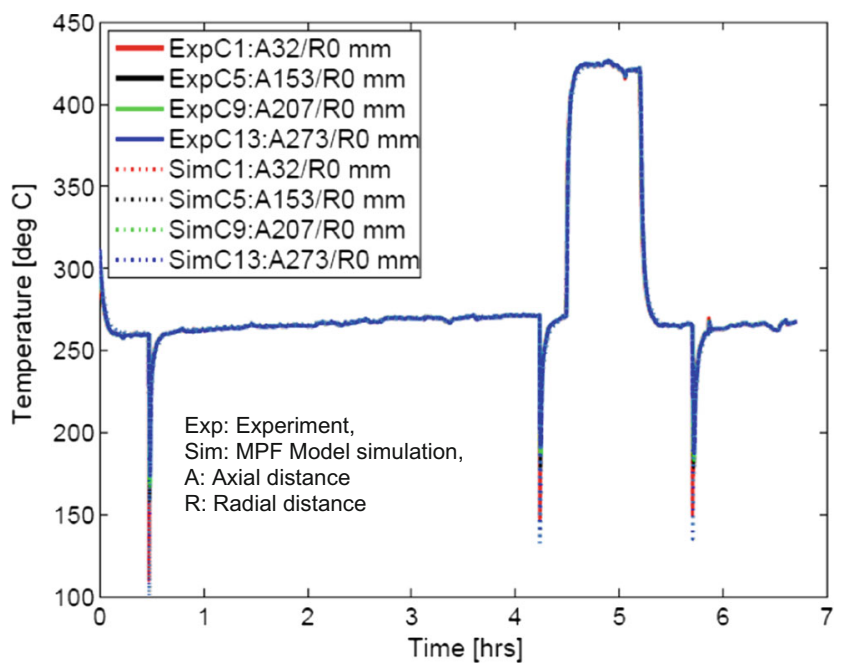

Fig. 9 Axial temperature distribution (PO-B10-16 experiment)

during the experiment along the length of the filter (axially 32 , 153,207 , and $273 \mathrm{~mm}$ from the front of the filter) which is similar to the trends observed during the passive oxidation experiment PO-B10-16. The MPF simulation model follows the experimental data within $\left(+18 /-15^{\circ} \mathrm{C}\right)$.

Figure 13 shows the temperature distribution measured by all 16 thermocouples and temperatures simulated by the MPF model at $5.63 \mathrm{~h}$ which is $15 \mathrm{~min}$ after the start of fuel dosing in order to compare the model predictability at the hightemperature region of the experiment. From Fig. 13, the MPF model follows the experimental data and the maximum temperature difference between the experimental and the simulation data is $\left(-20^{\circ} \mathrm{C}\right)$ at the upper right corner of the plot (filter substrate length $>250 \mathrm{~mm}$ and radius $>120 \mathrm{~mm}$ ).

From Fig. 13, the experimental filter substrate temperature shows an increase in temperature $\left(10-12{ }^{\circ} \mathrm{C}\right.$ at filter radiuses below $40 \mathrm{~mm}$ ) axially due to the local PM oxidation, and the substrate temperature close to the wall shows a lower increase

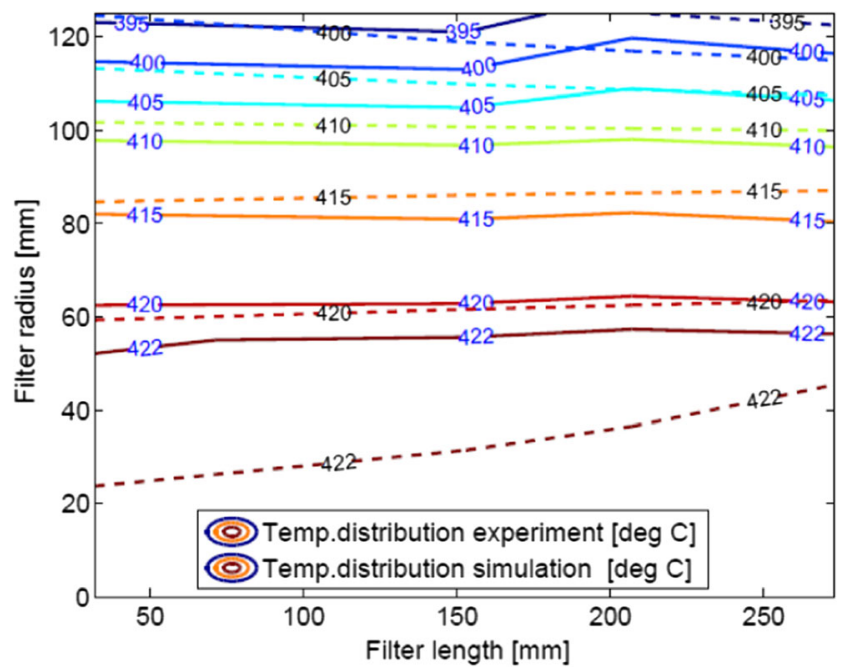

Fig. 10 Temperature distribution for PO-B10-16 experiment at $4.73 \mathrm{~h}$ (15 min after switching to PO engine operating condition)

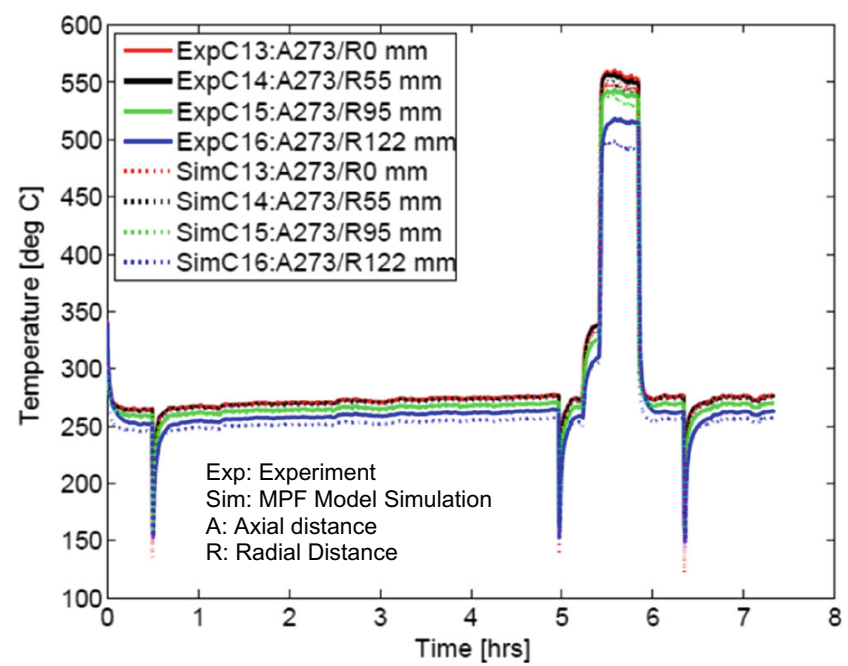

Fig. 11 Radial temperature distribution at filter outlet for AR-B10-1 experiment

in temperature axially $\left(5{ }^{\circ} \mathrm{C}\right.$ approximately) due to the dominant convection and radiative heat loss to the ambient compared to the local PM oxidation. From Fig. 13, the MPF simulation model also shows an increase in temperature $\left(4.4{ }^{\circ} \mathrm{C}\right)$ in the axial direction due to PM oxidation; however, the magnitude of the increase is low compared to the experimental data.

\subsection{PM Mass Retained}

Figure 14 shows the comparison of PM mass retained for the experimental data and simulation model along with the model cumulative for inlet PM and oxidation masses for PO-B10-16 experiment.

The measured PM masses at the end of each stage of the experiment (stage 1 to 4 ) are marked with plus markers in Fig. 14. $\mathrm{NO}_{2}$-assisted PM oxidation is the dominant mode of $\mathrm{PM}$ oxidation shown by a dashed line because of the $\mathrm{NO}_{2}$

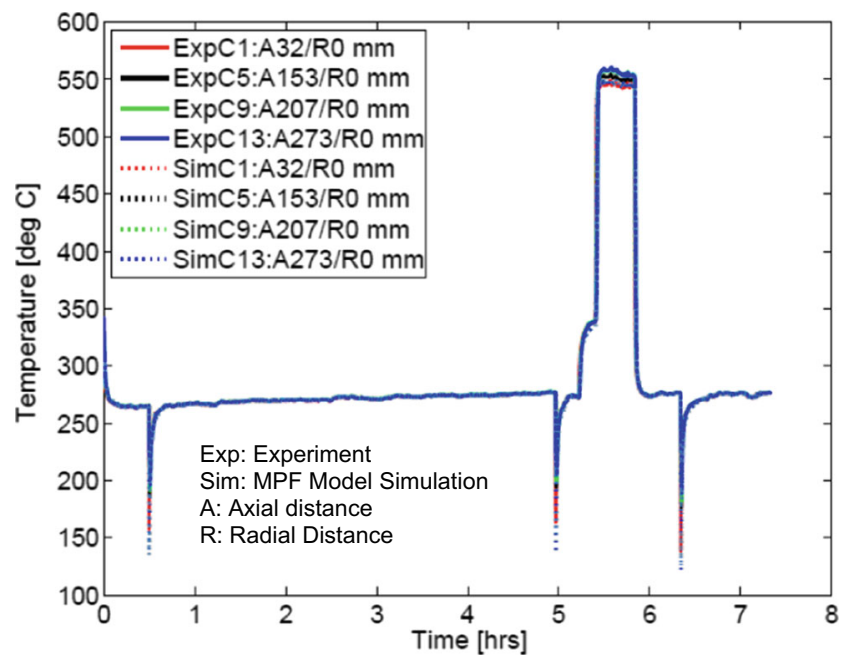

Fig. 12 Axial temperature distribution for AR-B10-1 experiment 


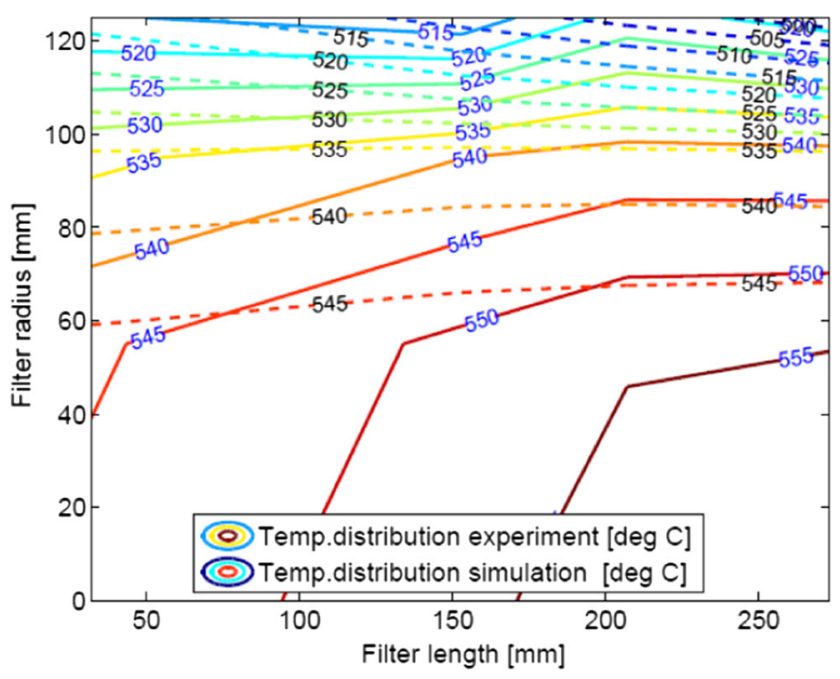

Solid lines: Experimental Data

Dashed lines: MPF Model Simulation

Fig. 13 Temperature distribution for AR-B10-1 experiment at $5.63 \mathrm{~h}$ (15 min after start of fuel dosing)

concentration (61 ppm). The thermal $\left(\mathrm{O}_{2}\right)$-assisted PM oxidation is low $(<1.3 \mathrm{~g})$ compared to $\mathrm{NO}_{2}$-assisted PM oxidation due to the lower exhaust gas temperature during the PM oxidation $\left(408^{\circ} \mathrm{C}\right.$ at 4.49 to $\left.5.22 \mathrm{~h}\right)$.

Table 6 shows the comparison of measured and simulated $\mathrm{PM}$ mass retained in the $\mathrm{CPF}$ at the end of each stage. From Table 6, the MPF model simulated the PM mass retained within the filter substrate with the maximum absolute error of $1.3 \mathrm{~g}$ between experimental and the simulated PM mass retained at the end of the stage 2 loading phase of the experiment.

Figure 15 shows the comparison of PM mass retained for the experimental data and simulation model along with the model cumulative for inlet PM and oxidation masses for AR-B10-1 experiment. From Fig. 15, thermal $\left(\mathrm{O}_{2}\right)$-assisted $\mathrm{PM}$ oxidation is the dominant mode of PM oxidation during

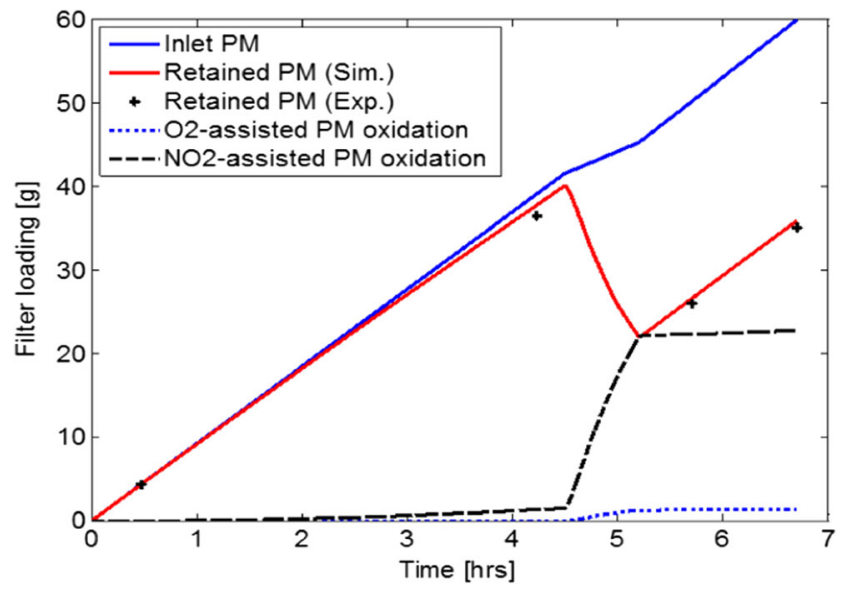

Fig. 14 Comparison of PM mass retained in the experimental data and simulation model along with the model cumulative for inlet PM and oxidation masses for PO-B10-16 experiment
Table 6 Comparison of experimental PM retained measured to MPF model output PM retained at the end of each stage for PO-B1016 experiment

\begin{tabular}{lcccl}
\hline Stage & $\begin{array}{l}\text { Time } \\
{[\mathrm{hrs}]}\end{array}$ & $\begin{array}{l}\text { Expt. } \\
{[\mathrm{g}]}\end{array}$ & $\begin{array}{l}\text { Model } \\
{[\mathrm{g}]}\end{array}$ & $\begin{array}{l}\text { Diff. } \\
{[\mathrm{g}]}\end{array}$ \\
\hline 1 & 0.47 & 4.3 & 4.3 & 0 \\
2 & 4.23 & 36.5 & 37.8 & 1.3 \\
3 & 5.70 & 26.0 & 26.6 & 0.6 \\
4 & 6.70 & 35.1 & 35.9 & 0.8 \\
\hline
\end{tabular}

active regeneration as shown by the dotted line because of the increased reaction rate due to the higher exhaust gas temperature $\left(530{ }^{\circ} \mathrm{C}\right.$ at 5.38 to $\left.5.82 \mathrm{~h}\right)$ and $\mathrm{O}_{2}$ concentration $(7.8 \%)$. The overall PM oxidized by thermal $\left(\mathrm{O}_{2}\right)$-assisted PM oxidation is $82 \%$ whereas the $\mathrm{NO}_{2}$-assisted $\mathrm{PM}$ oxidation is $18 \%$ due to the lower $\mathrm{NO}_{2}$ concentration in the exhaust gas.

Table 7 shows the comparison of experimental PM mass retained to the MPF model simulated PM mass retained. From Table 7, the maximum absolute error between the experiment and the simulation is $2.8 \mathrm{~g}$ at the end of stage 2 loading condition.

Figure 16 shows the PM mass loading distribution at the end of PM oxidation by passive oxidation during the PO-B1016 experiment. The minimum PM mass loading is $1.1 \mathrm{~g} / \mathrm{L}$ up to the filter radius of $80 \mathrm{~mm}$ and increases to a maximum value of $1.8 \mathrm{~g} / \mathrm{L}$ at the outer radius of the filter substrate. This is mainly due to the lower exhaust gas temperature at the outer radius of the filter due to the ambient convective and radiative heat transfer compared to the center of the filter substrate.

Figure 17 shows the PM mass loading distribution at the end of the PM oxidation during the AR phase of the experiment. From Fig. 17, the PM loading at the end of active regeneration varies significantly. The minimum PM mass loading is 0.2 to $0.4 \mathrm{~g} / \mathrm{L}$ up to a filter radius of $80 \mathrm{~mm}$ and increases to a maximum value of $2.4 \mathrm{~g} / \mathrm{L}$ at the outer radius of the filter substrate. This is mainly due to the lower exhaust gas

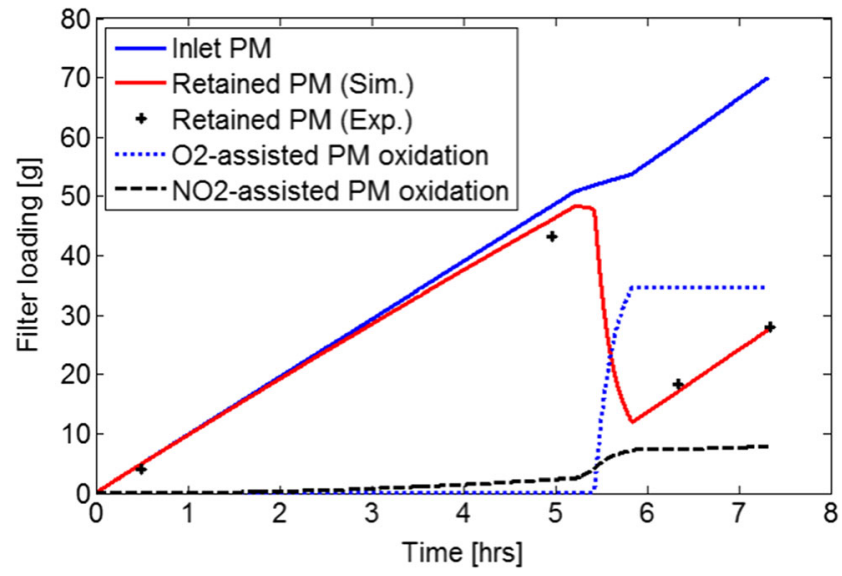

Fig. 15 Comparison of PM mass retained in the experimental data and simulation model along with the model cumulative for inlet PM and oxidation masses for AR-B10-1 experiment 
Table 7 Comparison of experimental PM retained measured to MPF model output PM retained at the end of each stage for AR-B10-1 experiment

\begin{tabular}{lcccc}
\hline Stage & Time & Expt. & Model & Diff. \\
\hline & {$[\mathrm{hrs}]$} & {$[\mathrm{g}]$} & {$[\mathrm{g}]$} & {$[\mathrm{g}]$} \\
1 & 0.49 & 4.0 & 4.8 & 0.8 \\
2 & 4.97 & 43.2 & 46.0 & 2.8 \\
3 & 6.34 & 18.3 & 17.0 & -1.3 \\
4 & 7.34 & 27.9 & 27.6 & -0.3 \\
\hline
\end{tabular}

temperature at the outer radius of the filter due to the ambient convective and radiative heat loss compared to the center of the filter substrate.

From the above simulation and experimental results analysis, the MPF model shows good capability in predicting temperature distribution, PM mass retained, and filter loading distribution within the filter substrate. For an ECU application, computational time is the key requirement for successful implementation of model-based control approach such as one presented in this paper. In general, the model with fine discretization is good for accuracy but takes long computational time. Hence, it is necessary to carry out a parametric study to determine the optimum required number of zones in the MPF model for aftertreatment control applications. This discretization study along with the detailed model validation is an ongoing work and will be covered in the next research paper.

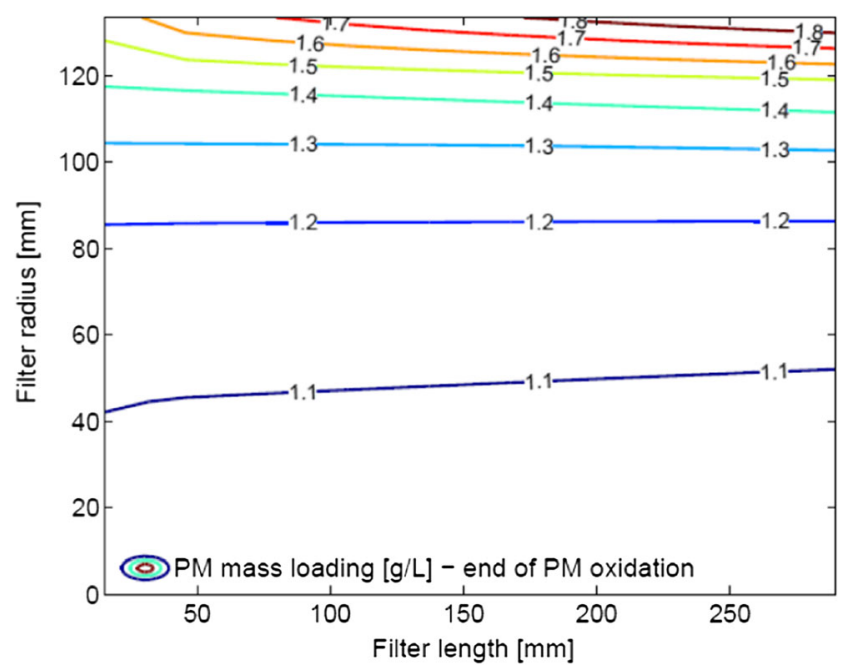

Fig. 16 Simulated PM mass loading distribution along axial and radial directions at $5.19 \mathrm{~h}$ - end of PM oxidation by passive oxidation for POB10-16 experiment

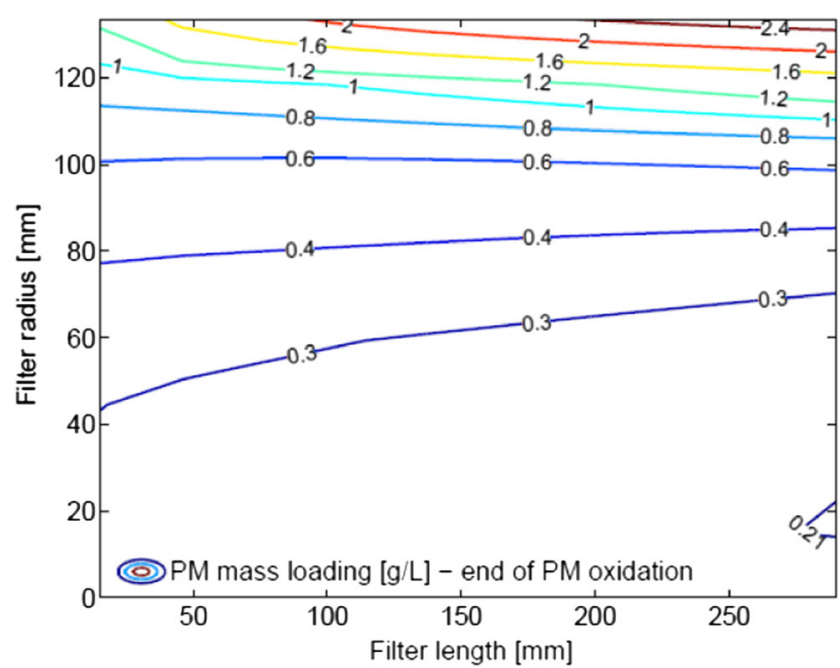

Fig. 17 Simulated PM mass loading distribution along axial and radial directions at $5.82 \mathrm{~h}$ - end of PM oxidation by active regeneration for ARB10-1 experiment

\section{Summary and Conclusions}

A new MPF model was developed for simulating filter substrate temperature and PM loading distribution within the filter. The model was parameterized through a two-step calibration procedure using 18 sets of data from the passive oxidation and active regeneration experimental data from references [3-6]. The model was calibrated with sample passive oxidation and active regeneration experimental data, and the model shows good capability in predicting the temperature distribution and filter loading within the filter substrate.

The specific conclusions from this work include

1. The MPF model to predict axial and radial temperature and filter loading distribution within the filter substrate was developed. The model accounts for heat transfer within and external to the filter and PM cake oxidation by $\mathrm{O}_{2}$ and $\mathrm{NO}_{2}$.

2. The radial temperature distribution initiates well before the inlet of the CPF and affects the distribution for the entire length of the $\mathrm{CPF}$. This radial temperature distribution can be characterized using thermal boundary layer equations. For the CPF presented in this study, $50 \%$ of overall radial temperature reduction is in the $20 \%$ of filter section close to the outer radius of the filter.

3. The detailed two-step MPF model calibration procedure was developed. A single set of PM kinetic parameters for each fuel type (Table 3) was found, and a single set of heat transfer coefficients (Table 4) was found for the all 18 runs.

4. The new MPF model simulation results show good capability in predicting temperature distribution (within $-24 /+$ 
$6{ }^{\circ} \mathrm{C}$ ), PM mass retained (within $-1.3 /+2.8 \mathrm{~g}$ ), and filter loading distribution within the $\mathrm{CPF}$.

Acknowledgments The authors would like to thank Kenneth Shiel and James Pidgeon of Michigan Technological University for recording the temperature distribution data presented in this work and Dr. Kiran Premchand for the assistance in 1-D model simulation data presented in this work.

\section{Appendix A-MPF Model Development Equations}

The total volume of each zone $(V)$, empty volume $\left(V_{e}\right)$, and filter volume $\left(V_{f}\right)$ are [11]

$$
\begin{aligned}
& V_{i, j}=\pi\left(r_{i}^{2}-r_{i-1}^{2}\right) \Delta L_{j} \\
& V_{e_{i, j}}=N_{c_{i}} d^{2} \Delta L_{j} \\
& V_{f_{i, j}}=V_{i, j}-V_{e_{i, j}}
\end{aligned}
$$

The inlet PM is assumed to be deposited uniformly over the entire volume of filter; hence, mass of PM deposited in each zone is calculated as

$m s_{i, j}=\frac{m s_{t} V_{i, j}}{V_{t}}$

The average thickness of PM cake in each zone is calculated using total PM mass, PM density, and channel geometry as follows [21]:

$t s_{i, j}=\frac{1}{2}\left[d-\sqrt{d^{2}-\frac{m s_{i, j}}{\frac{N c_{t}}{2} \Delta L_{i, j} \rho_{s}}}\right]$

The empty volume while accounting for PM is calculated as follows $\left(V_{e s}\right)$ :

$$
V_{e s_{i, j}}=\frac{N c_{i}}{2}\left[\left(d-2 t s_{i, j}\right)^{2},+, d^{2}, \Delta, L_{j}\right]
$$

Finally, the PM cake volume is calculated as

$V s_{i, j}=V_{i, j}-V f_{i, j}-V_{e s_{i, j}}$

The detailed calculations and assumptions in discretization are explained in reference [11].

Filter Temperature Equations

The energy balance in the filter is affected by (a) heat conduction along the length of the filter (axial conduction), (b) heat conduction along radial direction of the filter (radial conduction), (c) convection between filter and channel gas, (d) energy released during oxidation of PM cake, and (e) heat transfer due to radiation exchange between channel surfaces. The energy flow through wall is neglected as there will be no distinction between inlet and outlet channels [11]. Hence, the energy balance equation for the filter is

$$
\begin{aligned}
& \left(\rho_{s} c_{s} V s_{i, j}+\rho_{f} c_{f} V_{f_{i, j}}\right) \frac{d T f_{i, j}}{d t} \\
& =\dot{Q}_{\text {cond.axial }}+\dot{Q}_{\text {cond.radial }}+\dot{Q}_{\text {conv }}+\dot{Q}_{\text {reac }}+\dot{Q}_{\text {rad }}
\end{aligned}
$$

where $T f$ is the filter substrate temperature.

The axial and radial conduction along the length of the filter is calculated using resistance node methodology [11, 18]:

$\dot{Q}_{\text {cond.axial }}=\lambda_{i, j} A f_{i, j}\left[\frac{T f_{i, j+1}-T f_{i, j}}{\frac{1}{2}\left(\Delta L_{j+1}+\Delta L_{j}\right)}+\frac{T f_{i, j-1}-T f_{i, j}}{\frac{1}{2}\left(\Delta L_{j-1}+\Delta L_{j}\right)}\right]$

$Q_{\text {cond.radial }}=\lambda_{i, j} A r_{i, j}\left[\frac{T f_{i+1, j}-T f_{i, j}}{\operatorname{In}\left(r c_{i+1} / r c_{i}\right)}+\frac{T f_{i, j-1}-T f_{i, j}}{\operatorname{In}\left(r c_{i} / r c_{i-1}\right)}\right]$

$A f_{i, j}=\frac{V f_{i, j}+V s_{i, j}}{\Delta L_{j}}$

$A r_{i, j}=2 \pi \Delta L_{j}$

$\lambda_{i, j}=\frac{\lambda_{f} V f_{i, j}+\lambda_{s} V s_{i, j}}{V f_{i, j}+V s_{i, j}}$

The convection heat transfer between filter and channel gas is calculated using the following equations $[11,16]$ :

$\dot{Q}_{\mathrm{conv}}=h_{g} A s_{i, j}\left(T_{i, j}-T f_{i, j}\right)$

The convective heat transfer coefficient $\left(h_{\mathrm{g}}\right)$ is calculated using the following fully developed Nusselt number correlation based on flow Peclet number through the wall for $R e_{w}<3$ is given as [18]

$N u_{\text {inlet }}=2.98+0.60 P e_{w}-0.143 R e_{w}$

$N u_{\text {outlet }}=2.98-0.40 P e_{w}$

In the MPF model, as there is no distinction between inlet and outlet channel, the average Nusselt number is used for computing the heat transfer coefficients and it is given as

$N u_{\text {avg }}=N u_{\text {inlet }}+N u_{\text {outlet }}=\frac{h_{g} d}{k_{g}}$

The combined surface area As is calculated as follows [11]:

$A s_{i, j}=\frac{N c_{i}}{2}\left\lfloor 4\left(d-2 t s_{i, j}\right)+4 d\right\rfloor \Delta L_{j}$ 
The energy released during exothermic reactions is given by [11]

$$
\begin{aligned}
& \dot{Q}_{\text {reac }, \text { th }}=-\frac{m s_{i, j}}{\rho_{s}} \dot{S} c_{(t h)} \Delta H_{\text {reac }, \text { th }} \\
& \dot{Q}_{\text {reac }, N O_{2}}=-\frac{m s_{i, j}}{\rho_{s}} \dot{S}_{\left(N_{2}\right)} \Delta H_{\text {reac } N O_{2}} \\
& \dot{Q}_{\text {reac }}=\dot{Q}_{\text {reac,th }}+\dot{Q}_{\text {reac }, \mathrm{NO}_{2}}
\end{aligned}
$$

where $\dot{S} c_{(\text {th })}$ is the PM mass lost due to thermal $\left(\mathrm{O}_{2}\right)$ oxidation of PM and $\dot{S} c_{\left(\mathrm{NO}_{2}\right)}$ is the PM mass oxidized due to $\mathrm{NO}_{2}-$ assisted combustion.

The gas energy balance equation for the channel gas entering and leaving the zone is given by

$$
\begin{aligned}
& \rho c_{p} A s_{i, j} \Delta L_{j} \frac{d T_{i, j}}{d t}=\dot{m}_{i, j} c_{p}\left(T_{i, j-1}-T_{i, j}\right)-\dot{Q}_{\mathrm{conv}} \\
& \dot{m}_{i, j}=\dot{m}_{\text {total }} \frac{V e s_{i, j}}{\sum_{\mathrm{i}} V e s_{i, j}}
\end{aligned}
$$

where $T$ is the average channel gas temperature. The average channel gas temperature that lumps inlet and outlet channel is used in the gas energy balance equations.

Radiation between the channel surfaces

In the MPF model, each zone is treated as an enclosure as shown in Fig. A1. The surface 3 is the substrate wall with PM cake (black body radiation), and surfaces 1 and 2 are the inlet and outlet of this enclosure (the gas interface between the zones) which are assumed to be black for simplicity of the analysis and moreover radiation escaping surfaces 1 and 2 will be absorbed in to the adjacent black surface.

Assuming channel gas is completely transparent to thermal radiation and the surfaces are black, the net radiation heat transfer between filter wall (surface 3 ) can be determined as follows [19]:

$\dot{Q}_{\text {rad }}=-A s_{i, j}\left(F_{3-1}\left(J_{3}-J_{1}\right)+F_{3-2}\left(J_{3}-J_{2}\right)\right.$

$J_{1}=\sigma T_{i, j-1}^{4}$

$J_{2}=\sigma T_{i, j}^{4}$

$J_{3}=\sigma T f_{i, j}^{4}$

The effect of internal radiation is very small at lower temperatures and could be more important over $600{ }^{\circ} \mathrm{C}$ and could improve the model accuracy during uncontrolled regeneration events [23].

PM Oxidation Equations

The PM oxidation equations include PM oxidation by thermal $\left(\mathrm{O}_{2}\right)$ - and $\mathrm{NO}_{2}$-assisted reactions. The chemical reaction expression for thermal $\left(\mathrm{O}_{2}\right)$ oxidation is [11]

$$
\begin{gathered}
\mathrm{C}_{(\mathrm{s})}+a_{o_{2}} \mathrm{O}_{2} \rightarrow 2\left(a_{o_{2}}-0.5\right) \mathrm{CO}_{2}+2\left(1-a_{o_{2}}\right) \mathrm{CO} \\
\left(0.55 \leq a_{o_{2}} \geq 0.90\right)
\end{gathered}
$$

Similarly, the reaction equation for $\mathrm{NO}_{2}$-assisted oxidation is given by $[16,23]$

$$
C(s)+\mathrm{a}_{\mathrm{NO} 2} \mathrm{N0}_{2} \rightarrow \mathrm{a}_{\mathrm{NO} 2} \mathrm{NO}+\left(2-\mathrm{a}_{\mathrm{NO} 2}\right) \mathrm{CO}+\left(\mathrm{a}_{\mathrm{NO} 2}-1\right) \mathrm{CO}_{2}
$$$$
\left(1.2 \leq \mathrm{a}_{\mathrm{NO} 2} \geq 1.8\right)
$$

The oxidation of PM mass on the surface due to thermal and $\mathrm{NO}_{2}$-assisted oxidation is equal to

$\dot{S}_{c_{(\mathrm{th})}}=-\left(S_{p} \rho_{i, j} Y_{i, j, o_{2}} k_{o_{2}}\right) \frac{W_{c_{(s)}}}{a_{o_{2}} W_{o_{2}}}$

$\dot{S}_{c\left(\mathrm{NO}_{2}\right)}=-\left(S_{p} \rho_{i, j} Y_{i, j, \mathrm{NO}_{2}} k_{\mathrm{NO}_{2}}\right) \frac{W_{c_{(s)}}}{a_{\mathrm{NO}_{2}} W_{\mathrm{NO}_{2}}}$

The Arrhenius reaction rate for thermal- and $\mathrm{NO}_{2}$-assisted reaction is equal to

$k_{o_{2}}=A_{o_{2}} T f_{i, j} \exp \left[-E_{o_{2}} /\left(R_{u} T f_{i, j}\right)\right]$

$k_{\mathrm{NO}_{2}}=A_{N O_{2}} T f_{i, j} \exp \left[-E_{\mathrm{NO}_{2}} /\left(R_{u} T f_{i, j}\right)\right]$

Velocity Equations

From Depcik et al. [11], the average inlet channel velocity can be determined as

$\left.u_{I}\right|_{z=0}=\frac{\dot{m}_{\text {total }}}{\rho \frac{N c_{t}}{2}(d-2 . \overline{t s})^{2}}$

Using the Eq. (47), the radial zone velocity (mass flow is axially same for each zone) is calculated as

$\left.u_{I_{i}}\right|_{z=0}=\frac{\dot{m}_{i, j}}{\rho_{i, j} \frac{N c_{i}}{2}\left(d-2 \cdot \overline{t s_{i}}\right)^{2}}$

where $\overline{t_{i}}$ is the average PM cake thickness in each radial zone

Fig. A1 Schematic of an enclosure (zone) for the radiation heat transfer model

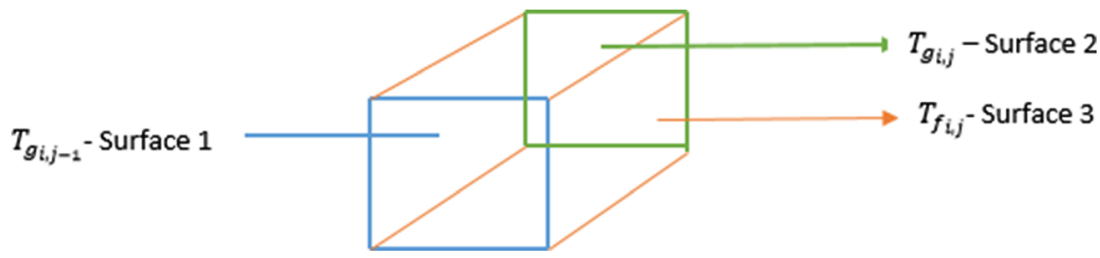


Table B1 CPF inlet temperatures measured by C1-C4 thermocouples and temperature factor

\begin{tabular}{|c|c|c|c|c|c|c|}
\hline $\begin{array}{l}\text { Radial distance } \\
\text { in } \mathrm{mm}\end{array}$ & Temperature ID & $\begin{array}{l}\text { Temperature } \\
\text { at } 0.30 \mathrm{~h} \text { in } \mathrm{C}\end{array}$ & $\begin{array}{l}\text { Temperature } \\
\text { at } 5.8 \mathrm{~h} \text { in } \mathrm{C}\end{array}$ & Diameter ratio & $\begin{array}{l}\text { Temperature } \\
\text { factor at stage } \\
1 \text { - loading } 0.3 \mathrm{~h}\end{array}$ & $\begin{array}{l}\text { Temperature factor } \\
\text { at active regeneration } \\
-5.8 \mathrm{~h}\end{array}$ \\
\hline 0 & C1 (measured) & 268.6 & 542.7 & 0.00 & 1.70 & 1.76 \\
\hline 55 & C2 (measured) & 268.9 & 539.8 & 0.41 & 1.72 & 1.63 \\
\hline 95 & C3 (measured) & 263.2 & 529.3 & 0.71 & 1.17 & 1.16 \\
\hline 122 & C4 (measured) & 255.6 & 513.1 & 0.91 & 0.42 & 0.44 \\
\hline \multirow[t]{4}{*}{133} & Ts (extrapolated) & 251.3 & 503.2 & 1.00 & 0.00 & 0.00 \\
\hline & $T_{m}$ (calculated) & 261.5 & 525.6 & & & \\
\hline & $T_{m} / T_{s}$ & 1.041 & 1.045 & & & \\
\hline & $\operatorname{Avg} T_{m} / T_{s}$ & 1.043 & & & & \\
\hline
\end{tabular}

Surface temperature (Ts) in Table B1 was extrapolated from C1-C4 thermocouple measurements as shown in Figs. B1 and B2

and $\frac{N c_{i}}{2}$ is the number of inlet channels in each radial zone.

From Depcik et al. [11], average velocity through the PM cake $\left(u_{s}\right)$ and wall layers $\left(u_{w}\right)$ is

$$
\begin{aligned}
& u_{s}=\frac{\dot{m}_{\text {total }}}{4 \rho \frac{N c_{t}}{2}(d-2 . \overline{t s}) L_{t}} \\
& u_{w}=\frac{u_{s}(d-2 . \overline{t s})}{d}
\end{aligned}
$$

Writing Eqs. (49) and (50) for each radial zone is

$$
\begin{aligned}
u_{s_{i}} & =\frac{\dot{m}_{i, j}}{4 \rho_{i, j} \frac{N c_{i}}{2}\left(d-2 . \overline{t s_{i}}\right) L_{t}} \\
u_{w_{i}} & =\frac{u_{s_{i}}\left(d-2 . \overline{t s_{i}}\right)}{d}
\end{aligned}
$$

From Depcik et al. [11], average velocity through the inlet channel $\left(u_{I}\right)$ and outlet channel $\left(u_{I I}\right)$ is

$\left.u_{I}\right|_{j}=\left.u_{I}\right|_{j-1}-\frac{4 u_{s}}{\mathrm{~d}-2 . \overline{t s}} \Delta L_{j-1}$

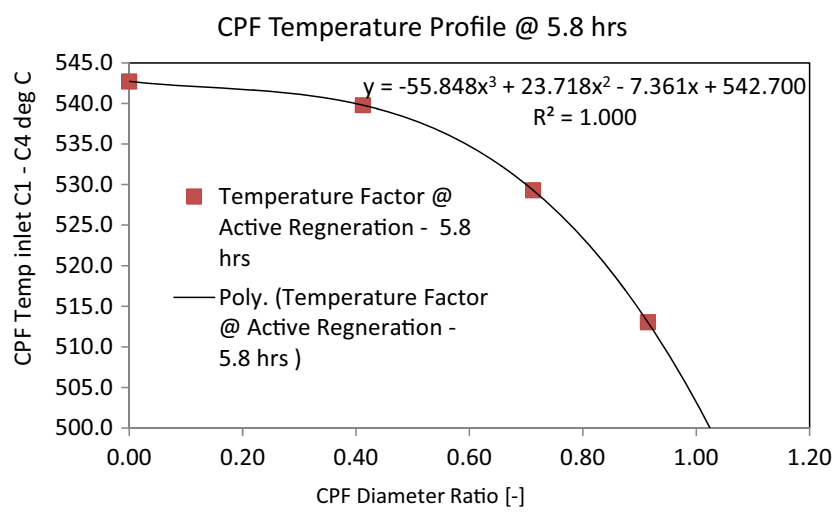

Fig. B1 CPF temperature profile at $5.8 \mathrm{~h}$
$\left.u_{I I}\right|_{j}=\left.u_{I I}\right|_{j-1}+\frac{4 u_{w}}{d} \Delta L_{j-1}$

Writing Eqs. (53) and (54) for each radial zone,

$\left.u_{I}\right|_{i, j}=\left.u_{I}\right|_{i, j-1}-\frac{4 u_{s_{i}}}{\mathrm{~d}-2 \cdot \overline{t s_{i}}} \Delta L_{j-1}$
$\left.u_{I I}\right|_{i, j}=\left.u_{I I}\right|_{i, j-1}+\frac{4 u_{w_{i}}}{d} \Delta L_{j-1}$

The detailed formulations of Eqs. (48, 49, 52, 53, and 54) are found in reference [11].

Filter Temperature Boundary Conditions

At the inlet of MPF model (for nodes $i=1$ to imax and $j=1$ ), the temperature profile is calculated using the thermal boundary layer Eq. (12) and the CPF inlet temperature at a given location. At the center of the filter (for $i=1, \mathrm{j}=1$ to jmax) due to the symmetry, the boundary condition equals to [11]

$\left.\frac{d T f}{d r}\right|_{r=0}=0$

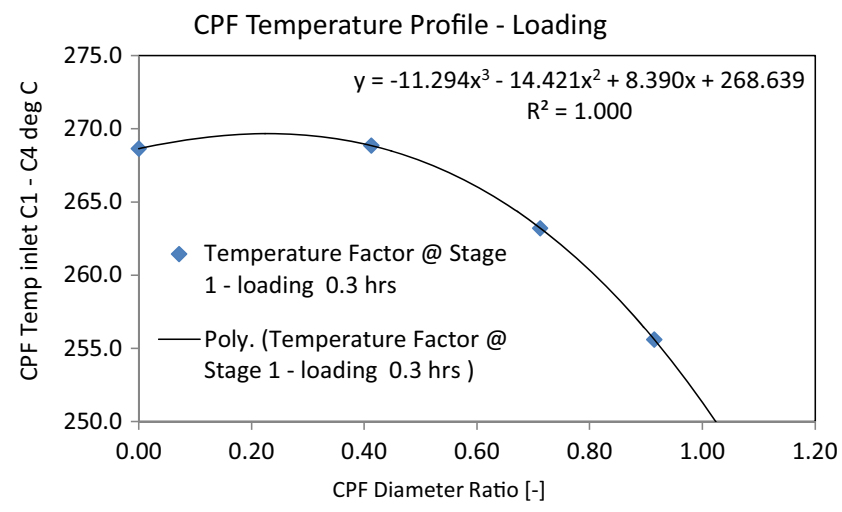

Fig. B2 CPF temperature profile at stage 1 loading $0.3 \mathrm{~h}$ 


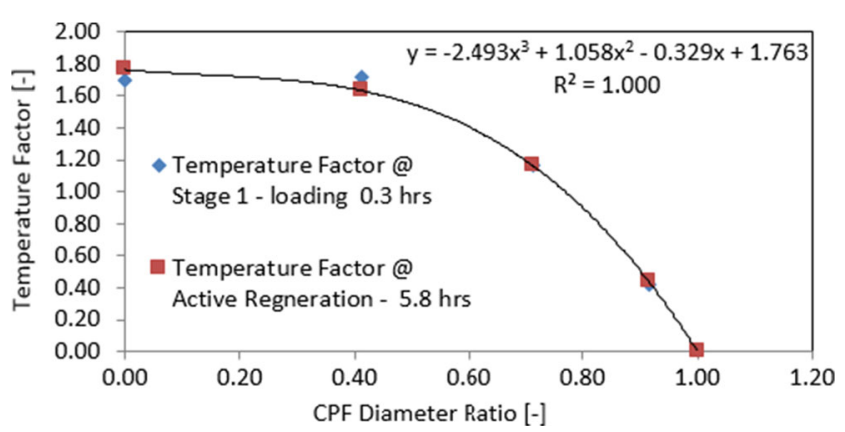

Fig. B3 Temperature factor

At the exterior of the CPF ( $i=\operatorname{imax}, j=2$ to jmax $)$, the following equation is used to calculate the radial conduction heat transfer

$$
\begin{aligned}
\dot{Q}_{\text {cond.radial }}= & \lambda_{i, j} A r_{i, j} \frac{T f_{i-1, j}-T f_{i, j}}{\operatorname{In}\left(r c_{i} / r c_{i-1}\right)} \\
& +h_{\mathrm{amb}} A_{\mathrm{amb}}\left(T_{\mathrm{amb}}-T f_{i, j}\right) \\
& +\varepsilon_{r} \sigma A_{\mathrm{amb}}\left(T f_{\mathrm{amb}}^{4}-T f_{i, j}^{4}\right)
\end{aligned}
$$

The surface area of the CPF is calculated as follows

$$
A_{\mathrm{amb}}=\pi D \Delta L_{j}
$$

\section{Appendix B-Thermal Boundary Layer Curve Fits and Coefficients}

As shown in Fig. 6, the temperature factor for all 18 runs is identical. Hence, AR-B10-1 experiment was used as the reference experiment for calculation of thermal boundary layer coefficients. The temperatures measured by thermocouples $\mathrm{C} 1-\mathrm{C} 4$ were used for calculation of temperature factor.

The temperature factors [19] were calculated using Eq. 60 . The sample calculation at $\mathrm{R} 1=0 \mathrm{~mm}$ is shown as follows:

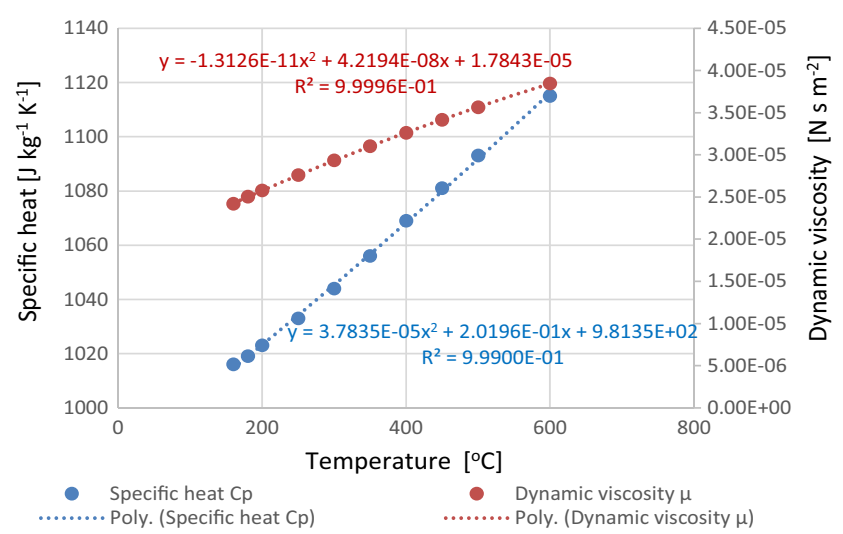

Fig. C1 Air properties' plot at $1 \mathrm{~atm}$ pressure [26]
Temparature factor $=\frac{T_{s}-T_{r}}{T_{s}-T_{m}}$

where $T_{m}=$ Mean exhaust gas temperature

$T_{s}=$ Wall inner surface temperature

$T_{r}=$ Temperature at a given radial location

Temperature factor @ R1, 0 mm @ 5.8 hrs $=\frac{503.2-542.7}{503.2-525.6}$ $=1.76$

Figure B3 shows the plots of temperature factors for stage 1 loading at $0.3 \mathrm{~h}$ (a sample point at lowtemperature region of the test) and active regeneration at $5.8 \mathrm{~h}$ (a sample point at high-temperature region) test conditions. From Fig. B3, it is evident that the temperature varies significantly between $0.3\left(262{ }^{\circ} \mathrm{C}\right)$ and $5.8 \mathrm{~h}$ $\left(523{ }^{\circ} \mathrm{C}\right)$, the temperature factor profile looks similar for both conditions, confirming that the one factor can be applied for the entire duration of the test. The following equation represents temperature factors of both test conditions with $R^{2}$ value of 1.00 (Fig. C1).

$$
\begin{aligned}
\text { Temperature Factor } @ \mathrm{x}= & -2.493 \mathrm{x}^{3} \\
& +1.0585 \mathrm{x}^{2}-0.3285 \mathrm{x} \\
& +1.7631
\end{aligned}
$$

Where $x$ is the CPF diameter ratio.

Using Eq. 60 and knowing the temperature at any radial location at the $\mathrm{CPF}$ inlet, the temperatures at the other radial locations can be determined as shown below

$\frac{T_{S}-T}{T_{S}-T_{m}}=F 1=$ Temperature Factor

$\frac{T_{m}}{T_{S}}=F 2=$ mean to surface temperature ratio

Combining Eqs. (62) and (63) yields

$\frac{T_{S}-T}{T_{S}-F 2 . T_{S}}=F 1$

$F 1\left(T_{S}-F 2 . T_{S}\right)+T-T_{S}=0$

Example calculation: To find temperature Ts, assume we have a temperature measurement $T=539.8{ }^{\circ} \mathrm{C}$ at $x=0.41$. From Eq. (61), $\mathrm{F} 1=1.63$ for $x=0.41$. Then substituting $\mathrm{F} 2=$ 1.043 (from Table B1), $\mathrm{F} 1=1.63$, and $T=539.8^{\circ} \mathrm{C}$ in Eq. (65), the $T_{\mathrm{s}}$ can be calculated as follows: 


$$
1.63\left(T_{S}-1.043 * T_{S}\right)+539.8-T_{S}=0
$$

and $T_{\mathrm{s}}=504.4{ }^{\circ} \mathrm{C}$. Similarly, temperatures at other locations can be determined using Eq. (62).

\section{Appendix C-Model Calibration Inputs}

The multi-zone model uses the following air properties relationship based on data in reference [26].

The Eqs. (66) and (67) were developed using the table values in reference [26] for specific heat and dynamic Figure $\mathrm{C} 1$ shows the plot of table values from reference [26] as a function of air temperature for specific heat and dynamic viscosity along with their model curve fits.....

Specific heat $=3.7835 \mathrm{E}-05 \mathrm{~T}^{2}-2.0196 \mathrm{E}-01 \mathrm{~T}$

$$
+9.8135 \mathrm{E}+02
$$

Dynamic viscosity $=1.3126 \mathrm{E}-11 \mathrm{~T}^{2}+4.2194 \mathrm{E}-08 \mathrm{~T}$

$$
+1.7843 \mathrm{E}-05
$$

Where $T$ is the temperature of the channel gas at each zone for the multi-zone model.

\section{References}

1. Rose, K., Hamje, H., Jansen, L., Fittavolini, C., Clark, R., Almena, M., Katsaounis, D., Samaras, C., Geivanidis, S., and Samaras, Z.: Impact of FAME content on the regeneration frequency of diesel particulate filters (DPFs). SAE Int. J. Fuels Lubr. 7(2):2014, doi: 10.4271/2014-01-1605

2. Rose, D., and Boger, T.: Different approaches to soot estimation as key requirement for CPF applications, SAE Technical Paper No.2009-01-1262,2009

3. Shiel,K.L., Naber, J., Johnson, J.H., and Hutton, C.R.: Catalyzed particulate filter passive oxidation study with ULSD and biodiesel blended fuel, SAE Technical Paper No. 2012-01-0837,2012, doi: 10.4271/2012-01-0837

4. Pidgeon, J., Naber, D N., and Johnson, J.H.: An engine experimental investigation into the effects of biodiesel blends on particulate matter oxidation in a catalyzed particulate filter during active regeneration, SAE Technical Paper No. 2013-01-0521, SAE Congress 2013

5. Shiel, K.L.: Study of the effect of biodiesel fuel on passive oxidation in a catalyzed filter, Master's Thesis, Michigan Technological University, 2012

6. Pidgeon, J.: An experimental investigation into the effect of biodiesel blends on particulate matter oxidation in a catalyzed particulate filter during active regeneration, Master's Thesis, Michigan Technological University, 2013

7. Kladopoulou, E.A., Yang, S.L., Johnson, J.H., Parker, C.G., Konstandopoulos, A.G.: A study describing the performance of diesel particulate filters during loading and regeneration - a lumped parameter model for controls applications, SAE Tech Paper No. 2003-01-0842, 2003
8. Nagar, N., He,X., Iyengar, V., Acharya, N., Kalinoski, A., Kotrba, A., Gardner, T., and Yetkin, A.: Real time implementation of DOC-CPF models on a production-intent ECU for controls and diagnostics of a pm emission control system, SAE Paper No 2009-01-2904, 2009

9. Mulone, V., Cozzolini, A., Abeyratne, P., Littera, D., Thiagarajan, M., Besch, M.C., and Gautam, M.: Soot modeling for advanced control of diesel engine aftertreatment, ASME ICEF2010-35160, 2010, doi:10.115/ICEF2010-35160

10. Mulone, V., Cozzolini, A., Abeyratne, P., Besch, M., Littera, D., Gautam, M.: Exhaust:CPF model for real-time applications, SAE Technical Paper No. 2011-24-0183,2011, doi:10.4271/2011-240183

11. Depcik, C., Langness, C., and Mattson, J.: Development of a simplified diesel particulate filter model intended for an engine control unit, SAE Technical Paper No. 2014-01-1559, 2014, doi:10.4271/ 2014-01-1559,2014

12. Konstandopoulos, A.G., Kostoglou, M., and Housiada, P.: Spatial non-uniformities in diesel particulate trap regeneration, SAE Technical Paper No. 2001-01-0908, 2001

13. Yi, Y.: Simulating the soot loading in wall-flow CPF using a threedimensional macroscopic model, SAE Technical Paper No. 200601-0264, 2006

14. Premchand, K.C., Surenahalli, H., and Johnson, J.: Particulate matter and nitrogen oxides kinetics based on engine experimental data for a catalyzed diesel particulate filter, SAE Technical Paper No. 2014-01-1553, 2014, doi:10.4271/2014-01-1553

15. Johnson, J.H., Naber, J.N., Parker, G., Yang, S., Stevens, A., and Pihl, J.: Experimental studies for CPF and SCR model, control system, and OBD development for engine using diesel and biodiesel fuels, DOE Report Number: DOE-2013-MTU-01-FINAL dated July 29,2013

16. Depcik, C., and Assanis, D.: Simulating area conservation and the gas-wall interface for one-dimensional based diesel particulate filter models, J. Eng. Gas Turbines Power, November 2008, Vol.130/ 062807-1, 2008

17. Bissett, E.J., Kostoglou, M., Konstandopoulos, A.G.: Frictional and heat transfer characteristics of flow in square porous tubes of wallflow monoliths. Chem. Eng. Sci. 84(2012), 255-265 (2012)

18. Kostoglou, M., Bissett, E.J., Konstandopoulos, A.G.: Improved transfer coefficients for wall-flow monolithic catalytic reactors: energy and momentum transport. Ind. Eng. Chem. Res. 51, 1306213072 (2012)

19. Cengel, Y.A.: Heat and mass transfer-a practical approach, McGraw-Hill Publication, Third Edition, ISBN-13: 978-0-07063453-4, 2007

20. Konstandopoulos, A.G., Kostoglou, M., Skaperdas, E., Papaioannou, E., Zarvalis, D., and Kladopoulou, E.: Fundamental studies of diesel particulate filters: transient loading, regeneration and aging, SAE Technical Paper No. 2000-01-1016, 2000

21. Koltsakis, G.C., Haralampous, O.A., Margaritis, N.A., Samras, Z.C., Vogt, C.-D., Ohara, E., Watanabe, Y., and Mizutani, T.: 3dimensional modeling of the regeneration in $\mathrm{SiC}$ particulate filters, SAE Technical Paper No. 2005-01-0953, 2005

22. Anderson Jr., J.D.: Computational fluid dynamics - the basics with applications. McGraw-Hill Publication, New York (1995). ISBN 007-113210-4

23. Koltsakis, G., Haralampous, O., Depcik, C., Ragonoe, J.C.: Catalyzed diesel particulate filter modeling. Rev. Chem. Eng. 29(1), 1-61 (2013). doi:10.1515/revce-2012-008

24. Martyr, A.J., and Plint, M.A.: Engine testing - the design, building, modifications and use of powertrain test facilities, ButterworthHeinemann Publications, ISBN-13: 978-0-08-096949-7, 2012

25. Nelder, J.A., Mead, R.: A simplex method for function minimization. Comput. J. 7(4), 308-313 (1965)

26. Cengel, Y.A., and Cimbala, J.M.: Fluid mechanics - fundamentals and applications, McGraw-Hill Publication, ISBN-13:978-0-07061197-9, 2008 